Examining Complex Links among Shyness, Fear Regulation, and Parental Emotional Socialization in the Prediction of Young Children's Socio-Emotional Functioning

by

\title{
William Hipson
}

A thesis submitted to the Faculty of Graduate and Postdoctoral Affairs in partial fulfillment of the requirements for the degree of

\author{
Master of Arts \\ in \\ Psychology \\ Carleton University \\ Ottawa, Canada
}

(C) 2017

William Hipson 


\begin{abstract}
The primary goal of this study was to examine a complex theoretical model linking shyness, fear regulation, parental emotion socialization, and indices of social adjustment in preschoolers. Participants were $N=262$ preschool children (ages 2-5 years; $M=3.23, S D=.51$ ). Parents rated children's shyness and fear regulation strategies in the Fall (Time 1) and early childhood educators assessed indices of children's social adjustment in the Spring (Time 2). Among the results, shyness was negatively associated with fear regulation and positively associated with socially withdrawn behaviours at preschool. A significant age moderated-mediation effect was also found, whereby fear regulation mediated the negative association between shyness and prosocial behaviour among older preschoolers, but not among younger preschoolers. Overall, the results provide some initial evidence to suggest that fear regulation may play a unique role in older preschoolers' social adjustment.
\end{abstract}




\section{Acknowledgements}

First and foremost, I would like to thank my supervisor, Dr. Robert Coplan, for his enduring guidance and support. Thank you imparting such a wealth of knowledge and for helping me transform my ideas into reality. I would also like to acknowledge the immense contribution of my colleague Dr. Daniel Séguin. Thank you, not only for your input and assistance in this project, but also for instilling in me a passion for research in developmental psychology and for teaching me how to ask deep questions and think "big picture".

I would like to extend my thanks to Dr. Scott Mirabile for letting me use and adapt his measure of emotion regulation, and for offering valuable insights about the results. I am also grateful for my thesis committee (Dr. Xiaobei Chen, Dr. Chris Davis, and Dr. Deepthi Kamawar) for their time and devotion to this work.

To the directors, educators, and parents from our participating childcare centres across Ottawa and Halifax: I offer my heartfelt gratitude for taking the time to participate in this research. This would not have been possible without their contributions. Furthermore, I would like to thank Laura Cater, Sam Davin, Laura Dodge, Emily Vanden Hanenburg, Carlotta Heymann, Annastasia Jickling, Maria Redden, Bronwen Schryver, Jamie Thompson, and Shawntel Whitten for their role in collecting and inputting the data.

To my parents, I thank you for encouraging me to pursue an education and to reach my fullest potential. Finally, to Erika Hipson, my wife and best friend. Thank you for endlessly supporting me in my studies and for always being there to listen to my thoughts and ideas. Without you, I may never have had the courage to pursue these goals. 


\section{Table of Contents}

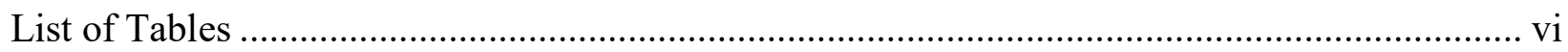

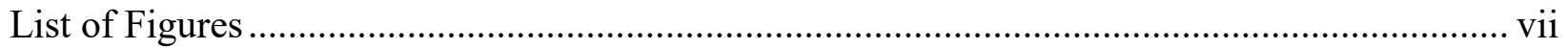

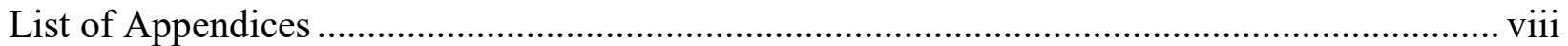

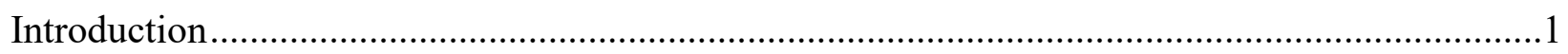

The Development of Emotion Regulation..........................................................................

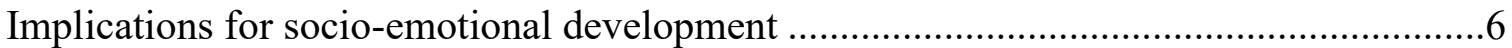

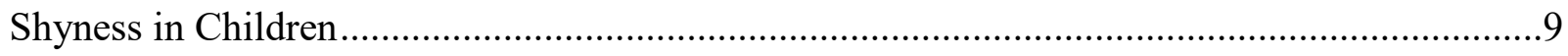

Shyness and Emotion Regulation................................................................................. 11

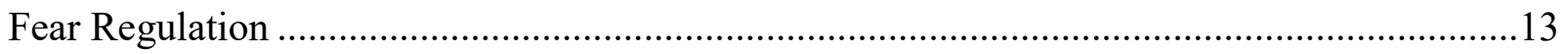

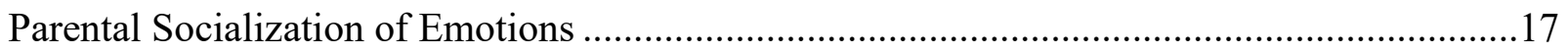

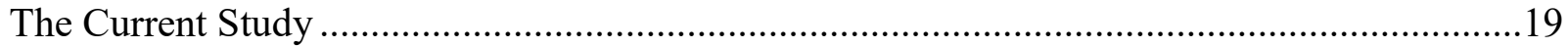

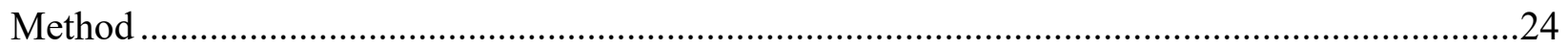

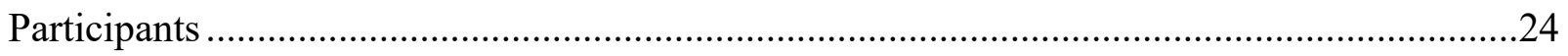

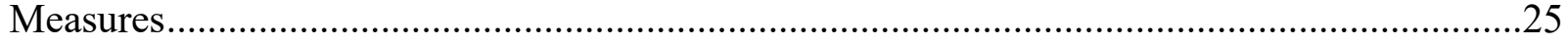

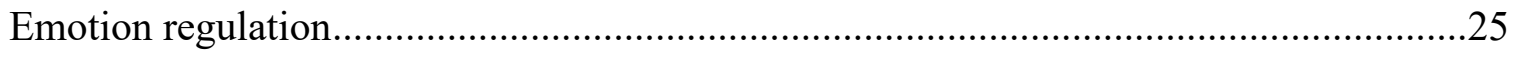

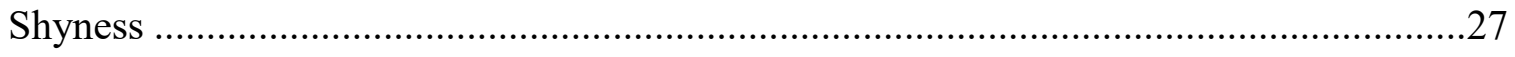

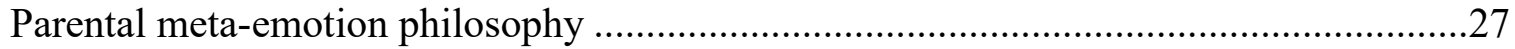

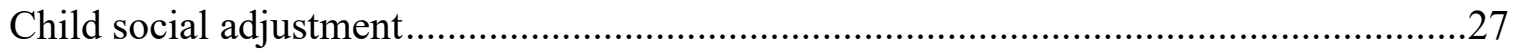

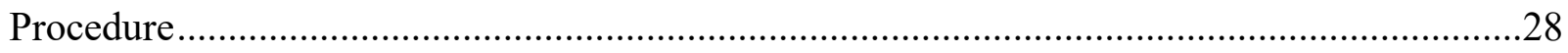

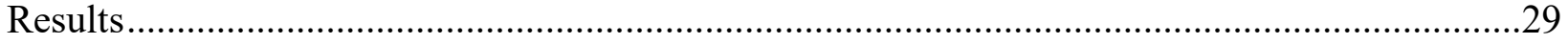

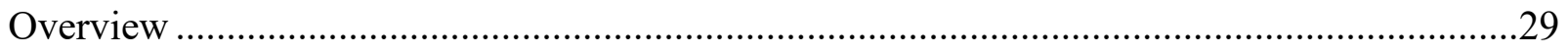

Factor Structure and Psychometric Properties of the ERSQ ............................................29

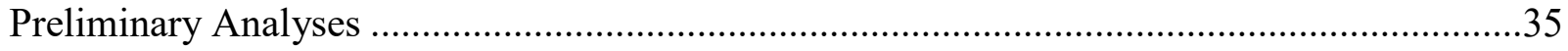

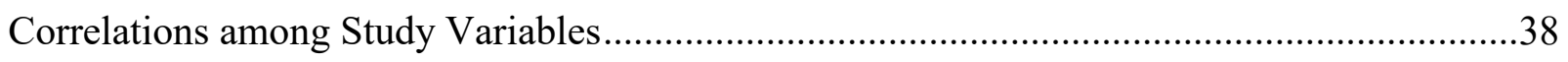

Mediation and Moderated-Mediation Analyses ..............................................................40

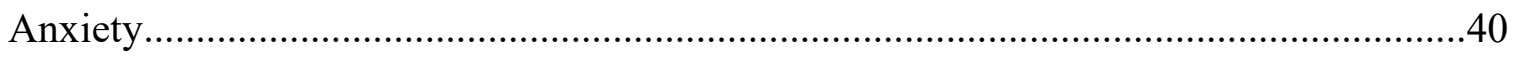

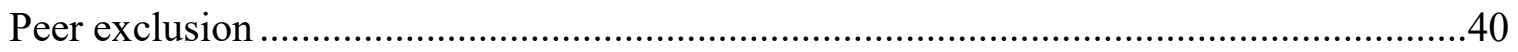

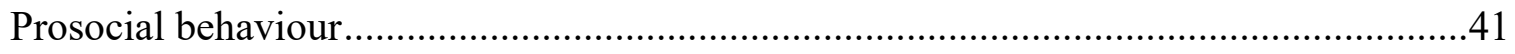

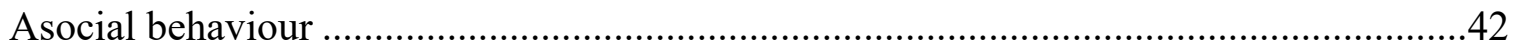




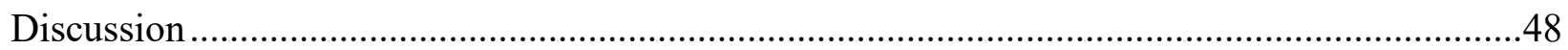

Measurement of Fear and Anger Regulation in Young Children .............................................49

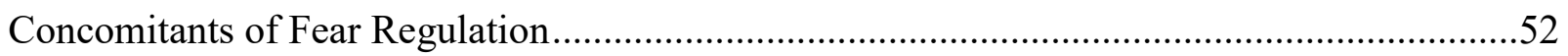

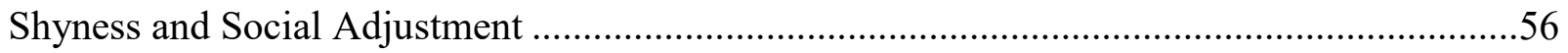

Shyness, Fear Regulation, and Adjustment: Moderated/Mediated Pathways..............................58

Emotion Coaching and Social Adjustment …………………................................................61

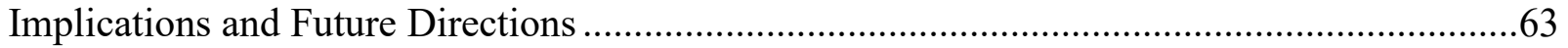

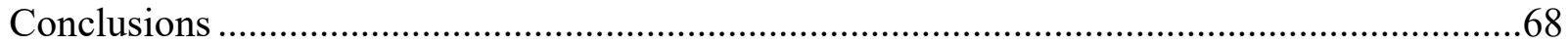

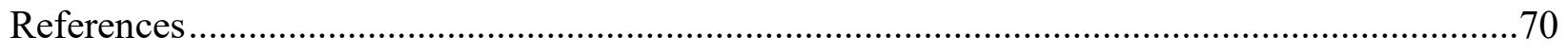

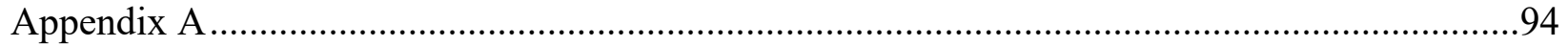

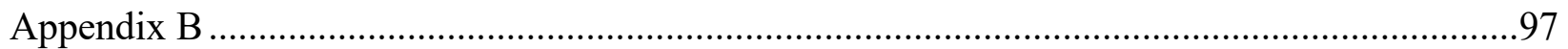

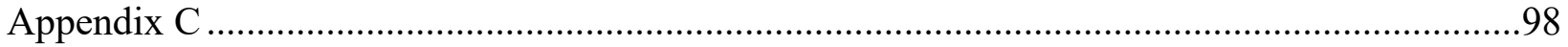

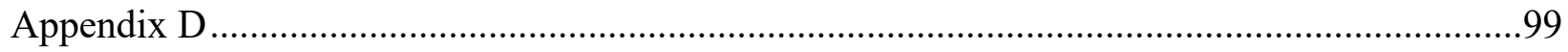

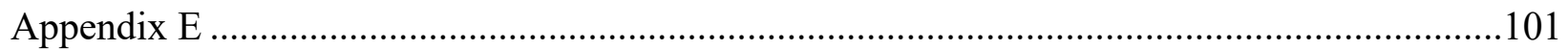

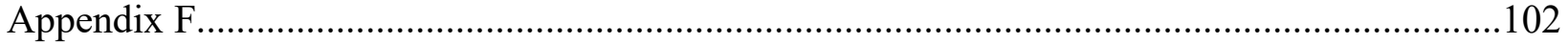

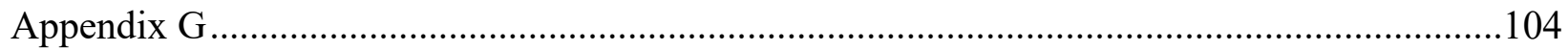

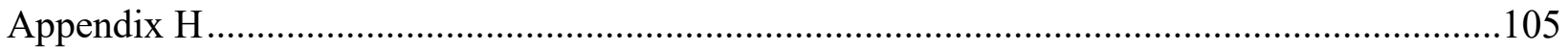

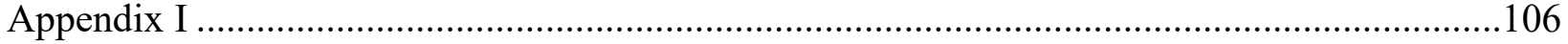

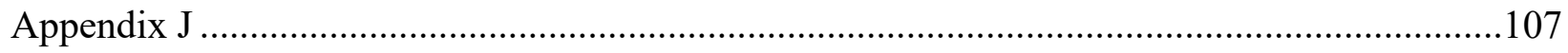

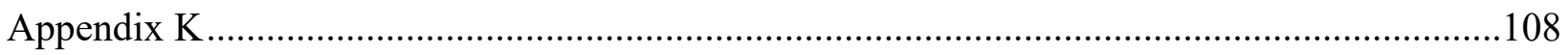

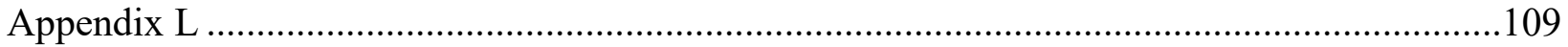




\section{List of Tables}

Table 1. Descriptive Statistics for Individual ERSQ Items ................................................30

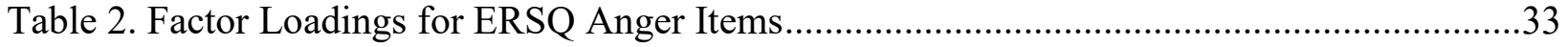

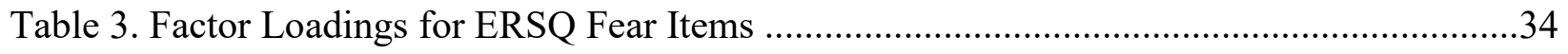

Table 4. Descriptive Statistics for All Study Variables .............................................................37

Table 5. Partial Correlations among Study Variables (Controlling for Age, Gender, and Parental

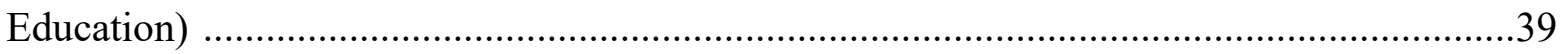

Table 6. Mediation and Moderated-Mediation Models Predicting Anxious Behaviours ..............43

Table 7. Mediation and Moderated-Mediation Models Predicting Peer Exclusion......................44

Table 8. Mediation and Moderated-Mediation Models Predicting Prosocial Behaviour ..............45

Table 9. Mediation and Moderated-Mediation Models Predicting Asocial Behaviour................46 


\section{List of Figures}

Figure 1. Hypothesized moderated-mediation model ....................................................22

Figure 2. Moderated-mediation model of shyness predicting prosocial behaviour mediated by fear regulation, conditional on child age 


\section{List of Appendices}

Appendix A: Emotion Regulation Skills Questionnaire (ERSQ) (Mirabile, 2014)....................94

Appendix B: Child Social Preference Scale (CSPS) (Coplan et al., 2004) ...............................97

Appendix C: Maternal Emotional Styles Questionnaire (MESQ) (Lagacé-Séguin \& Coplan,

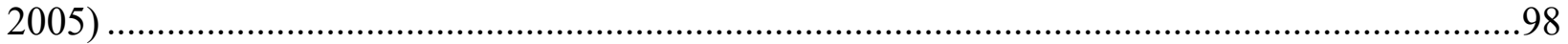

Appendix D: Child Behavior Scale (CBS) (Ladd \& Profilet, 1996) .......................................99

Appendix E: Email Invitation to Childcare Directors............................................................101

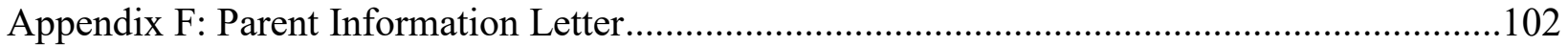

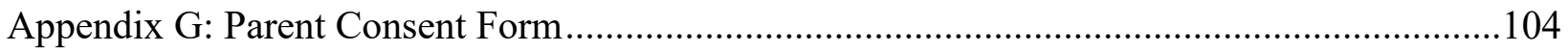

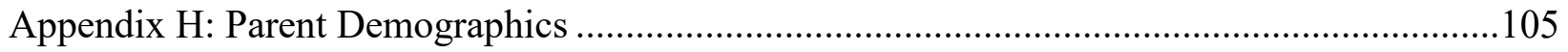

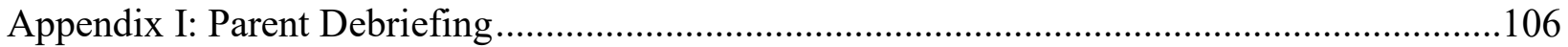

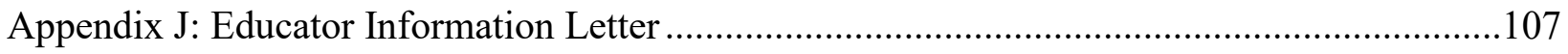

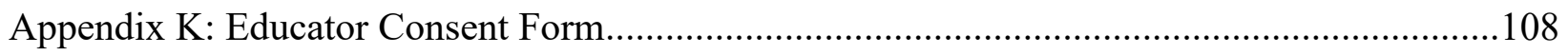

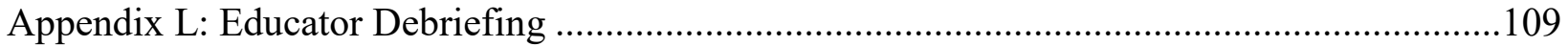


Examining Complex Links among Shyness, Fear Regulation, and Parental Emotional Socialization in the Prediction of Young Children's Socio-Emotional Functioning

The ability to control one's emotions is important for healthy socio-emotional functioning (Eisenberg, Spinrad, \& Valiente, 2016). For example, children who can refrain from losing their temper when upset, or overcome fear and anxiety during their first week at preschool, are likely to have better outcomes compared to those who succumb to their negative emotions (e.g., Spinrad et al., 2004). The term emotion regulation describes the action or ability of modulating emotion expression and experience in a way that is adaptive to a particular situation (Gross, 2013). Although emotions are believed to serve important functional purposes, such as signaling a salient change in the environment or indicating to others that a particular need is not being met (Campos, Mumme, Kermoian, \& Campos, 1994), it is often the case that successfully navigating the social world requires the ability to regulate those emotions, particularly when those emotions are of a negative valence (e.g., anger or fear). As such, emotion regulation is regarded as invaluable for promoting optimal social interactions with others (e.g., Blair et al., 2015).

The connection between emotion regulation and social competence is particularly salient among children. For instance, researchers have consistently found that emotion regulation is both concurrently and predictively positively related to indices of socio-emotional functioning (Blair et al., 2015; Eisenberg et al., 2003). In this regard, children who can regulate their emotions have more sophisticated social skills, are more accepted by peers, and experience less peer victimization in contrast to their dysregulated counterparts (Blair et al., 2015; Morelen, SouthamGerow, \& Zeman, 2016). Conversely, emotion dysregulation (the relative inability to adaptively regulate one's emotions) is implicated in the development of both externalizing (e.g., aggression) 
and internalizing (e.g., anxiety) problems (Feng, Shaw, \& Moilanen, 2011; Moran, Lengua, \& Zalewski, 2013). Children who are emotionally dysregulated tend to regulate negative emotions maladaptively, such as losing their temper when angry or hiding away from others when nervous or distressed. In extreme cases, emotion dysregulation is implicated in the development of clinical disorders, including anxiety and depression (Gramszlo \& Woodruff-Borden, 2015; Hurrell, Hudson, \& Schniering, 2015; Williams \& Woodruff-Borden, 2015). Indeed, many interventions for anxiety disorders focus on establishing adaptive emotion regulation strategies (Aldao, Jazaieri, Goldin, \& Gross, 2014; Mennin \& Fresco, 2014).

Currently, there has been substantial research concerning how emotion dysregulation is associated with children's externalizing problems, such as aggression and oppositional defiance (e.g., Blair, Denham, Kochanoff, \& Whipple, 2004; Calkins, Dedmon, Gill, Lomax, \& Johnson, 2002; Halligan et al., 2013), with a focus on the regulation of externalizing emotions (e.g., anger and frustration). In contrast, comparatively little is known about how emotion regulation may be involved in the development of internalizing problems, particularly in early childhood. For children who are shy or socially anxious, it may be especially pertinent to focus on their ability to regulate fear.

Accordingly, the primary purpose of this research was to examine a complex conceptual model linking shyness, fear regulation, and young children's socio-emotional functioning. Shyness is a temperamental characteristic linked with both heightened fear reactivity (Rubin \& Coplan, 2010) and the development of internalizing problems (e.g., Nelson et al., 2008). The ability to regulate fear was expected to at least partially account for (i.e., mediate) the relations between preschool children's temperamental shyness and indices of socio-emotional adjustment. Furthermore, it has been well-established that parental emotion socialization influences 
children's ability to understand and control emotions (Morris, Silk, Steinberg, Myers, \& Robinson, 2007). Accordingly, parenting characterized by more positive patterns of emotion socialization (emotion coaching) was expected to be particularly impactful (i.e., moderating effect) in the proposed mediated pathways from shyness to fear regulation to adjustment.

This thesis begins with an overview of emotional development and emotion regulation in early childhood, starting with the acquisition of emotion regulation and the concurrent and longitudinal socio-emotional implications of emotion dysregulation. This is followed with a description of shyness in early childhood and a rationale for exploring the specific role of fear regulation in shy children's social adjustment. The subsequent section includes a summarization and critical analysis of the extant literature of fear regulation, followed by an explanation of how the current study addresses the limitations of previous research. The next section explores the role of parental socialization of emotion, specifically how emotion coaching parenting may act as a protective factor for shy children. The literature review concludes with a complete description regarding the purpose and hypotheses of the current study, followed by a detailed account of the methodology and statistical analyses. Results and discussion are outlined in the final sections.

\section{The Development of Emotion Regulation}

Emotional development begins in infancy with the emergence of rudimentary basic emotions, such as joy, anger, and fear (Izard, 1991). These basic emotions are distinguished by distinct physiological, behavioural, and facial reactions, which lay the groundwork for the development of more complex emotions (Lewis, 2000). One of the basic components underlying a child's emotional response (particularly to negative emotions such as fear or anger) is reactivity. Reactivity refers to the frequency and intensity with which one responds to an emotion-eliciting stimulus (Eisenberg et al., 1995; Rothbart, 1989; Rothbart, Ahadi, \& Hershey, 
1994). Reactivity encompasses the physiological aspects of an immediate emotional response and is often measured with behavioural or psychophysiological indicators. This construct is also sometimes referred to as emotionality or negative emotionality when referring exclusively to negative emotions (e.g., Paulussen-Hoogeboom, Stams, Hermanns, \& Peetsma, 2007). As an example, the frequency and intensity of a child's anger in response to a frustration-eliciting event (e.g., losing television privileges) constitutes their anger reactivity.

Regulation consists of the automatic or intentional processes that seek to modulate a prepotent emotional response. Regarding negatively valenced emotions (i.e., fear and anger), the purpose of emotion regulation is often to deactivate or downregulate an emotional response (Rothbart et al., 1994), although it should be noted that emotion regulation can also consist of upregulation (e.g., attempting to intensify one's expression of happiness) (Dennis, 2006). It has been suggested that children are, at least to some degree, born with a rudimentary ability to downregulate their negative emotions. In infancy and toddlerhood this consists of the ease with which they can be soothed by others (i.e., soothability), namely, a parent or caregiver (Aureli, Coppola, Picconi, Grazia, \& Ponzetti, 2015). For the most part, however, very young children lack the ability to regulate their own emotions and thus require support and guidance from parents and caregivers in the form of external emotion regulation (Cole, Martin, \& Dennis, 2004).

Reactivity and regulation are viewed by contemporary temperament theorists as fundamental components of children's temperament and early personality (Rothbart \& Bates, 2006). Furthermore, there appear to be innate individual differences in reactivity and regulation that jointly contribute to the development of children's emotional and social skills (Calkins, Gill, Johnson, \& Smith, 1999; Eisenberg et al., 1995). Indeed, Eisenberg and colleagues (1995) 
suggested that a temperament profile characterized by low reactivity and high regulation is most conducive to social competence throughout development, as these children experience fewer and less intense negative emotions and are similarly more capable of regulating these emotions. Further evidence of this is provided in a more recent study, indicating that physiological indices of reactivity and regulation jointly predict internalizing behaviours among at-risk preschoolers (Moran, Izard, \& Hyde, 2014).

Notwithstanding, it is worth noting that, although researchers tend to make the distinction between reactivity and regulation, these constructs are not mutually exclusive. Infants who are more reactive to distressing or frustrating situations are more likely to have difficulties regulating these more frequent and intense emotions. Likewise, poor emotion regulation can lead to a further heightening of reactivity (Braungart-Rieker \& Stifter, 1996; Eisenberg, Fabes, Guthrie, \& Reiser, 2002). Nevertheless, there is compelling physiological and neurological evidence suggesting that those processes involved in initiating an emotional response are distinct from those involved in mediating or controlling this response (Dennis \& Hajcak, 2009). Perhaps most importantly, these early regulatory processes form the initial scaffolding for the development of more sophisticated, intentional regulatory behaviours or emotion regulation strategies (Braungart-Rieker, Hill-Soderlund, \& Karrass, 2010; Calkins et al., 2002).

The strategies with which children regulate their emotions vary across individuals, and these variations appear to be present from an early age. For example, Grolnick, Bridges, and Connell (1996) found evidence for discrete differences in the strategies that two-year-olds employ to regulate their emotions. These strategies have been broadly classified into three types: active, passive, and disruptive (Silk, Shaw, Skuban, Oland, \& Kovacs, 2006). Active strategies reflect a child's intentional attempts to change or modify a situation to reduce distress. As an 
example, in response to receiving a broken toy as a prize, a child using an active strategy may attempt to fix the broken toy or she may seek help from a nearby adult. In contrast, passive strategies are characterized by a child's attempt to reduce distress by disengaging from the situation. This typically includes behaviours such as self-soothing, distraction, and avoidance (Feng et al., 2008). Finally, there are disruptive strategies, which are not so much explicit strategies for regulating emotions per se, but represent an overt dysregulation of emotion (e.g., responding to distress by acting out verbally or physically). Although individuals may rely on a variety of strategies depending on contextual demands, in general children tend to employ a specific type of strategy with relative consistency, and their response styles tend to remain stable throughout early childhood and into adolescence (August et al., 2015).

Implications for socio-emotional development. Emotion regulation has important implications for children's social and emotional development throughout childhood and adolescence (e.g., Diener \& Kim, 2004). However, the preschool years (approximately 2 to 5 years of age) represent a particularly active period of socio-emotional development, as many children are introduced to formal education and structured care. For most children entering childcare, their regulatory abilities have only recently progressed from largely externally-driven (i.e., parent-facilitated) to internally-driven (i.e., via regulatory strategies) (Thompson \& Goodman, 2009). In these early social environments, emotion regulation predicts children's ability to succeed, not only academically, but also socially (Blair et al., 2004; Herndon et al., 2013). It is at this point that children learn effective ways of interacting with same-age peers, which involves skills such as communication, negotiation, and cooperation; all of which are largely dependent on emotion regulation (Zimmermann, Maier, Winter, \& Grossman, 2001). It is thus not surprising that children who are emotionally regulated also tend to be more socially 
competent (Blair et al., 2015; Di Maggio, Zuppulla, \& Pace, 2016; Eisenberg et al., 2003). For example, children who are emotionally well-regulated tend to engage in more prosocial behaviours toward peers, which includes helping others and responding with empathy (Eisenberg et al., 2006). Indeed, preschool children who are more physiologically regulated (i.e., able to reduce parasympathetic response to an emotional stimulus), in combination with optimal maternal socialization of emotion, tend to engage in more prosocial behaviours (Scrimgeour, Davis, \& Buss, 2016).

Children who are emotionally well-regulated are also more likely to engage in behaviours that promote the development of social skills and friendships. Calkins, Gill, Johnson, and Smith (1999) found that preschool children who were more reactive to frustration and employed more maladaptive regulatory strategies (e.g., venting) were more likely to engage in conflicts with peers and less able to cooperate. More recently, in a sample of at-risk boys, Chang, Shelleby, Cheong, and Shaw (2012) reported that highly regulated children at three years of age were more socially competent in school and home contexts at six years of age. Thus, emotion regulation appears to foster behaviours that promote positive social interactions with peers. In turn, wellregulated children are more likely to be accepted by peers and have greater opportunities to build and maintain friendships (Blair et al., 2014; Blair et al., 2015). Indeed, this makes conceptual sense, as one is more likely to choose as a friend someone who can refrain from losing their temper. Emotion regulation may be an even stronger predictor of friendship quality in later childhood and adolescence, since respect among adolescent peers is garnered through emotional disinterest (i.e., acting cool).

Just as adaptive emotion regulation is associated with optimal social and emotional outcomes, emotion dysregulation is related to more maladaptive social behaviours. Children's 
problem behaviours are generally classified in terms of internalizing and externalizing behaviours (Campbell, 2006). Internalizing behaviours typically involve retreating or withdrawing from one's external environment. Thus, those who are highly internalizing keep their emotions and thoughts to themselves. In contrast, externalizing behaviours are typically disruptive to the self or others, and frequently comprise physical or verbal displays of aggression. These broad clusters of problematic behaviours in children demonstrate early precursors or risk factors for the development of clinical disorders, whereby unmitigated internalizing behaviour is typically associated with risk of anxiety disorders, and excessive externalizing behaviour is often associated with risk of conduct-related disorders (Eisenberg et al., 2009).

In general, children who are emotionally dysregulated are at risk for both internalizing and externalizing problems (Di Maggio et al., 2016; Eisenberg, Cumberland, Spinrad, Fabes, \& Shepard, 2001; Feng et al., 2011; Moran et al., 2014). However, these associations may be more nuanced, given that emotion regulation encompasses all emotions, including anger, fear, sadness, and even happiness (Gross, 2013). In this regard, some researchers have begun to parse apart the associations between regulation of specific emotions and social outcomes in childhood. For example, Zeman, Shipman, and Suveg (2002) examined children's regulation of sadness and anger in relation to internalizing and externalizing problems. Consistent with the notion that there are content specific associations between different emotions and behaviour problems, results indicated that anger dysregulation contributed more to externalizing problems, whereas sadness dysregulation contributed more to internalizing problems. As such, it is important to consider how regulation of specific emotions contribute uniquely to children's social adjustment. For instance, depending on children's temperament, certain emotions may be inherently easier or 
more difficult to regulate than others, and, consequently, have lesser or greater bearing on children's social adjustment.

\section{Shyness in Children}

Shyness is a temperamental trait characterized by wariness and unease in the face of social novelty (e.g., encountering a stranger) (Asendorpf, 1990), as well as self-consciousness and embarrassment in situations of perceived social evaluation (Crozier, 1995). Particularly in early childhood, this construct shares considerable conceptual overlap with other terms used in the extant literature, including behavioural inhibition (Kagan, Reznick, Clarke, Snidman, \& Garcia-Coll, 1984) or fearful temperament (Rapee \& Coplan, 2010). For the purposes of this thesis, these terms will be considered functionally equivalent. Shy children are thought to experience elevated physiological reactivity in response to social situations (particularly novel ones) (Fox et al., 2005), leading to feelings of anxiety that may hinder opportunities to engage in peer interactions and group play (Coplan, Ooi, \& Nocita, 2015; Coplan, Rubin, Fox, Calkins, \& Stewart, 1994). From a motivation perspective, shyness is characterized by an approachavoidance conflict, whereby a desire for social interaction is simultaneously inhibited by feelings of social avoidance (triggered by social fear and anxiety) (Asendorpf, 1990). As such, in early social contexts shy children are prone to reticent behaviours, which entails hovering on the outskirts of peer group activities seemingly unsure of whether to join in (Coplan et al., 1994).

Shyness has been linked to adjustment difficulties throughout childhood and adolescence, particularly along the internalizing dimension (Rubin, Coplan, \& Bowker, 2009). Moreover, extreme shyness is related to increased risk of depression and anxiety, most notably, social anxiety disorder (Chronis-Tuscano et al., 2009; Clauss \& Blackford, 2012; Schwartz, Snidman, \& Kagan, 1999). During early childhood, as children's social repertoire takes shape, shyness is 
related to difficulties interacting successfully with peers. Shy children tend to be less socially competent and have lower self-worth and, thus, are at an increased risk of experiencing peer victimization and rejection (Coplan et al., 2013; Coplan, Findlay, \& Nelson, 2004a; Crozier, 1995; Hart et al., 2000). For instance, Coplan, Arbeau, and Armer (2008) found that shy children were more likely to experience peer difficulties (i.e., loneliness, peer rejection) in kindergarten. Furthermore, temperamentally shy children are less competent in negotiating challenging social situations and will often resort to passive avoidance when faced with new or difficult social situations (Walker, Henderson, Degnan, Penela, \& Fox, 2014). Such avoidant behaviours are potentially effective in reducing immediate anxiety, but are often associated with long-term negative outcomes. Furthermore, these maladaptive responses may be reinforced over time, and as a result, shy children may find it increasingly difficult to integrate themselves into peer groups (Coplan, Wilson, Frohlick, \& Zelenski, 2006).

In later childhood and adolescence, shy children are at an increased risk for loneliness and are more likely to withdraw from peers (Prior, Smart, Sanson, \& Oberklaid, 2000). Stable and increasing levels of shyness throughout mid-to-late childhood are further associated with increased anxiety and depression in early adolescence (Karevold, Ystrøm, Coplan, Sanson, \& Mathiesen, 2012). Although the majority of temperamentally shy children do not become depressed or socially anxious and are able to lead highly successful lives (e.g., Biederman et al., 2001), these studies and others demonstrate the importance of determining which factors (both internal and environmental) may contribute to negative outcomes associated with shyness.

A few studies have assessed outcomes associated with shyness among preschool children, revealing that shy preschoolers (ages 4-6) tend to engage in more solitary activities (e.g., playing with blocks alone) (Coplan, Ooi, Rose-Krasnor, \& Nocita, 2014) and more frequently display 
anxious behaviours in childcare (Sette, Baumgartner, \& Schneider, 2014). However, comparatively less is known about these associations among younger preschoolers (ages 3-4). It can be speculated that among very young preschoolers, shyness may be comparatively more benign in terms of its impact on early social relationships. For example, nonsocial forms of play, including solitary and parallel play, are relatively normative among preschool children (EggumWilkens et al., 2014; Smith, 1978), and may thus be viewed less negatively by peers. Indeed, shy preschoolers may evoke fewer negative responses from peers compared to exuberant and impulsive children who may often become involved in disputes among peers (Morales, Beekman, Blandon, Stifter, \& Buss, 2015).

However, as children enter formal education and social evaluative pressures become more salient, the negative social implications of shyness may become more apparent. Peers who were once content to have shy children as a quiet playmate may later eschew them in favour of more sociable companions. Furthermore, as self-conscious features of shyness become increasingly prevalent throughout early childhood (Eggum-Wilkens, Lemery-Chalfant, Aksan, \& Goldsmith, 2015), the relative 'cost' of shyness and its emotional and behavioural concomitants may concordantly increase with age. Regardless, little is known about the potential mechanisms linking shyness with aspects of socio-emotional adjustment among very young children.

\section{Shyness and Emotion Regulation}

A recent body of research suggests that emotion regulation may be one mechanism linking shyness and social adjustment. In a longitudinal study, Penela and colleagues (2015) found that shyness (behavioural inhibition) in two- and three-year-olds was associated with more passive regulatory strategies (e.g., avoidance, self-soothing), which predicted decreased social competence in middle childhood. In other words, shyness was associated with maladaptive 
emotion regulation, which, in turn, predicted deficits in social competence. This is most likely attributable to the fact that passive emotion regulation (e.g., avoidance, self-soothing, etc.) may often provide short-term relief to anxiety, but tends to be associated with more negative outcomes over time (Aldao, Nolen-Hoeksema, \& Schweizer, 2010). Indeed, shy children are more likely to respond to novelty with high negative reactivity (Kagan, Snidman, \& Arcus, 1998), which may promote avoidant behaviours instead of active, problem-solving behaviours (Hane, Fox, Henderson, \& Marshall, 2008). In line with these findings, Kingsbury, Coplan, and Rose-Krasnor (2013) found that shy children use more internalizing coping strategies, including worrying, ruminating, self-pitying, and self-blaming, which appears to mediate the association between shyness and children's anxious and depressive symptomatology. Cumulatively, these findings suggest that shy children rely more on passive strategies to manage and cope with negative emotions, which, in turn, contributes to social adjustment difficulties.

In general, there is emerging evidence suggesting that emotion regulation contributes to shy children's social adjustment. However, one striking limitation of previous research is the lack of specificity regarding which emotions might be most implicated in shy children's social adjustment. Conceptually, emotion regulation encompasses all emotions, although for practical reasons most studies have focused exclusively on the ability to regulate anger, as it is easier to objectively measure. Nevertheless, it appears that emotion regulation is not necessarily a domain-general skill, but rather, is emotion-specific and varies between individuals. In other words, some children may be adept at regulating their anger though may struggle to regulate sadness and fear (Hourigan, Goodman, \& Southam-Gerow, 2011). Frequently used measures of emotion regulation (e.g., Emotion Regulation Checklist, Shields \& Cicchetti, 1997; Emotion Regulation Questionnaire, Gross \& John, 2003) provide indices of general regulatory ability, 
which fail to distinguish between individuals' ability to regulate specific emotions. For shy children, it makes conceptual sense to focus on those emotions that lead to internalizing behaviours, since these children are less likely to have difficulty regulating anger and more likely to struggle with fear and anxiety regulation (Zeman et al., 2002). As such, the current study examined the underlying role of fear regulation in helping to explain associations between shyness and social adjustment in preschool children.

\section{Fear Regulation}

In the emotion regulation literature, there is a noticeable paucity of research specific to the regulation of fear (i.e., the ability to control and manage the expression and experience of fear). Fear is a basic, hardwired reaction to a real or imagined threat (Izard, 1991). From a functionalist perspective, humans experience fear because it serves an adaptive, evolutionarily advantageous function (Rosen \& Schulkin, 1998); namely, it urges one to attend to and avoid physical danger. This can be contrasted with anxiety, which is a relatively enduring state characterized by worry or unease, often concerning events or situations where outcomes are uncertain. Nevertheless, fear and anxiety are intimately interrelated, in that excessive or poorly regulated fear can precipitate or exacerbate anxiety.

In infancy and early childhood, fear manifests in a variety of ways and across multiple contexts. At roughly six months of age, most infants exhibit stranger anxiety, whereby they respond to unfamiliar adults with wariness (Brooker et al., 2013; Field, 2008). Children may later begin to develop specific fears or phobias toward certain objects or situations, many of which may not represent a realistic threat (Evans, Gray, \& Leckman, 1999). Although fear may be deemed to be functionally adaptive - particularly in situations that are truly threatening excessive fear and anxiety interfere with normal daily functioning and can impede progress in 
accomplishing goals. Moreover, for those with an anxiety disorder, fear can be crippling and debilitating. Thus, even though very few young children experience fear and anxiety to such a personally devastating degree, the ability to control one's fear in response to environmental demands serves a valuable purpose, particularly in social situations where fear has little to no adaptive value.

Buss (2011) argued that fear regulation is context-dependent, suggesting that it is important to examine the context in which one expresses fear rather than simply examining its frequency. There are many fear-eliciting situations that, due to their threatening properties, warrant a full-blown fear response. In such high-threat situations (e.g., being approached by a dangerous stranger), if a child reacts with intense fear and anxiety it is inaccurate to deem such a response as exemplifying poor fear regulation. Conversely, in a low-threat situation (e.g., being approached by a friendly stranger), reacting with fear would aptly represent a form of fear dysregulation because the intensity of the fear response is incompatible with the characteristics of the situation. In this regard, fear dysregulation is conceptualized as a mismatch between the response to the fear-eliciting situation and the contextual threat.

Buss (2011) classified toddlers as fear regulated or fear dysregulated based on this apparent mismatch between their fear response and the contextual threat of the situation. As an example, an intense fear reaction elicited by a low-threat situation constituted fear dysregulation. Results from this longitudinal study indicated that toddlers with dysregulated fear profiles were more likely to exhibit anxious and withdrawn behaviours a few years later. Of note, fear dysregulation predicted increased risk for anxiety even after controlling for shyness (behavioural inhibition). In subsequent studies, Buss and colleagues (Buss et al., 2013; Buss, Davis, Ram, \& Coccia, 2017) explored the association between dysregulated fear in toddlers and social anxiety 
symptoms during kindergarten. Overall, those toddlers who exhibited heightened fear in a lowthreat context were more likely to exhibit socially anxious behaviours upon entering kindergarten.

The conceptual mechanisms that underlie the association between fear dysregulation and socially withdrawn behaviours remain mostly speculative in nature. There is some evidence to suggest that an avoidance bias of perceived social threat may link fear dysregulation in social contexts to later social wariness and withdrawal (Humphreys, Kircanski, Colich, \& Gotlib, 2016; Lonigan, Vasey, Phillips, \& Hazen, 2004; Morales, Pérez-Edgar, \& Buss, 2015). This suggests that fear dysregulation may be associated with a propensity toward threat avoidance, which, in turn, subsequently increases maladaptive social behaviours. Indeed, threat avoidance shares conceptual and behavioural similarities with passive emotion regulation, whereby negative emotions can be coped with by attending away from the distressing situation (Graziano, Calkins, \& Keane, 2011; Grolnick et al., 1996). Taken together, these findings provide compelling evidence that fear dysregulation plays a potentially significant and unique role in the development of anxiety and social wariness.

The studies by Buss and colleagues $(2011 ; 2013 ; 2017)$ provide intriguing insights into the role of fear dysregulation as a potential precursor of social anxiety in children. However, to more fully understand the complex role of fear regulation in children's development, some limitations must be addressed. First and foremost, fear dysregulation was operationalized as high fear response in low-threat situations, and thus focused on the extent to which children reacted to fear-eliciting stimuli. This may obfuscate the distinction between an emotional reaction and the regulation of that emotion. As noted by Gross (1998; 2013), the process of emotion regulation assumes that: (1) an emotional reaction is occurring; and (2) immediately following, automatic or 
intentional processes seek to regulate this response. Thus, the operationalization of fear dysregulation in research by Buss (2011) seems more characteristic of the initial emotional response and less so of the ensuing regulatory behaviours or strategies.

Admittedly, emotion regulation research in young children is inherently characterized by the reliance on behavioural indicators, whereby it is necessary to infer regulation based on behaviours during an ongoing emotional response. The lines are often blurred between what can be characterized as an emotional reaction versus emotion regulatory behaviours (Thompson, 2011). Although these two processes are often presented as conceptually distinct, in practice it is more difficult to separate the contributions of emotional reactions to regulation, and vice versa. Nevertheless, young children rely on certain behaviours as a means of dealing with and controlling their emotions during an emotional response, and these behaviours can be measured reliably via direct observation as well as through reliable informants (i.e., parents or educators). Indeed, by assessing children's emotion regulation strategies, researchers can gain further insight into which behaviours are effective in regulating emotions across a variety of situations and contexts.

Previous research on emotion regulation strategies has devoted considerably less attention to young children (younger than 5 years) compared with older, school-age children. Consequently, our understanding of the early development of fear regulation strategies is virtually nonexistent. Although Buss and colleagues (Buss et al., 2011; 2013; 2017) assessed fear dysregulation in toddlers, it has already been addressed that these studies included only observations of children's immediate fear response, rather than observations of the strategies children used to regulate their emotions. This gap in the literature prompts a crucial unanswered question pertaining to fear regulation in shy children: are shy children's social adjustment issues 
solely the result of heightened fear reactivity, or is it a tendency toward maladaptive fear regulation strategies that contributes to poor social adjustment? If, indeed, maladaptive fear regulation is a relevant factor in shy children's social adjustment, this begs an additional question: what role does parenting play in addressing and (potentially) intervening in children's maladaptive fear regulation?

\section{Parental Socialization of Emotions}

Children's understanding of emotions and how they deal with emotions are greatly shaped by parents' socialization of emotions (e.g., Cole, Dennis, Smith-Simon, \& 2009). Researchers have identified three ways in which parents contribute toward the socialization of children's emotions: (1) through modelling of their own emotion expression and regulation; (2) their reactions to children's emotional expressions; and (3) explicit coaching and discussion of emotions (Eisenberg, Cumberland, \& Spinrad, 1998; Halberstadt, 1991; Katz, Maliken, \& Stettler, 2012).

Gottman, Katz, and Hooven (1996) coined the term parental meta-emotion philosophy to describe parents' thoughts and feelings about their own emotions, as well as their thoughts and feelings about their children's emotions. Through intensive interviews with parents, they identified two types of parental meta-emotion philosophies: emotion coaching and emotion dismissing. Parents who are emotion coaching acknowledge the importance of emotions and recognize that their child's negative emotions represent opportunities for intimacy and teaching. Furthermore, emotion coaching parents are more likely to problem-solve with their child and help set goals and strategies for dealing with distressing situations. Emotion dismissing parents, on the other hand, are more likely to view their child's negative emotions as undesirable or even 
potentially harmful. These parents are more likely to respond to their child's negative emotions dismissively or punitively and less likely to offer guidance for dealing with negative emotions.

Parental meta-emotion philosophy not only contributes to children's understanding and expression of emotions, but also to their ability to regulate emotions. Parents who endorse an emotion coaching philosophy are more likely to engage in parenting behaviours that promote the development of emotion regulation in their children (Gottman et al., 1996). For instance, emotion coaching parents encourage their child to openly discuss their feelings which facilitates a parasympathetic response and may subsequently instill in children a better sense of control over their emotions (Katz et al., 2012). Additionally, the explicit coaching of strategies for dealing with negative emotions provides scaffolding for children's development of intrinsic regulatory strategies. Indeed, emotion-coaching parenting may lead to better academic and social outcomes in children through the modelling and instruction of adaptive emotion regulation strategies (Cunningham, Kliewer, \& Garner, 2009; Shipman et al., 2007). The benefits of emotion coaching parenting extend beyond early childhood. Emotion coaching parenting promotes the use of adaptive coping strategies, such as problem-solving and distraction, in adolescents as well (Lagacé-Séguin \& Gionet, 2009).

Although emotion coaching parenting has been generally associated with children's emotion regulation, the role of this approach in the development and implications of childhood shyness remains largely unexplored. Aspects of positive parenting, such as warmth and support tend to predict positive adjustment in shy children (e.g., Coplan et al., 2008; Grady, Karraker, \& Metzger, 2012), whereas more negative parenting aspects, such as coerciveness and overprotectiveness are associated with poor adjustment (Coplan, Reichel, \& Rowan, 2009). Notwithstanding, Gottman and colleagues (1996) acknowledged that parental meta-emotion 
philosophy is not synonymous with authoritative parenting (i.e., warm and supportive parenting). Indeed, parents can exhibit high degrees of warmth toward their children, but still be somewhat dismissive towards their child's negative emotions. For this reason, it is important to examine the specific function of parental meta-emotion philosophy in shy children's social adjustment. In keeping with previous research (e.g., Lagacé-Séguin \& Gionet, 2009), it was speculated that emotion coaching parenting would serve as a protective factor for children who are temperamentally at risk for socio-emotional adjustment difficulties.

\section{The Current Study}

It has been well established that emotion regulation is a pivotal component of positive social adjustment, and that parental socialization of emotion also plays an important role (e.g., Davis \& Buss, 2012; Morris et al., 2007; Root, Byrne, \& Watson, 2015). There is some evidence to suggest that associations between shyness and indices of socio-emotional functioning are mediated (i.e., partially accounted for) via a pathway through general emotion regulation (Penela et al., 2015). However, fear dysregulation also appears to play a unique and specific role in the prediction of early socially anxious behaviours (Buss et al., 2013). Thus, shy children's relative lack of abilities to regulate fear may help to account for their later experiences of social adjustment difficulties, particularly in the realm of internalizing behaviours (Buss, 2011; 2013; Zeman et al., 2002).

Notwithstanding, very little is currently understood about fear regulation in young children. This paucity of research may be at least partially due to a lack of validated measures that focus specifically on children's ability to regulate fear. A comprehensive review of the extant literature revealed only one measure that probes the emotion regulation strategies that young children use when they are experiencing fear. The recently developed Emotion Regulation 
Skills Questionnaire (ERSQ; Mirabile, 2014) has demonstrated some initial promise as a parentreport measure assessing young children's fear regulation strategies. However, the psychometric properties of this measure have not been rigorously tested. Published studies (Mirabile, 2014; $2015)$ using this measure included relatively small sample sizes $(n=81)$ that precluded more sophisticated statistical analyses (i.e., factor analyses) to support the conceptually-derived subscales.

Accordingly, the first goal of the proposed study was to provide validation of the ERSQ as an assessment of young children's fear regulation strategies. The ERSQ was originally developed to assess children's general use of adaptive (e.g., problem-solving, support seeking) versus maladaptive (e.g., avoidance, suppression) emotion regulation strategies in response to the expression of several different emotions (sadness, happiness, anger, and fear). For the purposes of this study, it was adapted to focus on children's specific strategies for regulating fear and anger, making it possible to examine differences in the strategies used to regulate anger compared to fear. Although this measure was conceived as containing two subscales (adaptive and maladaptive), it was expected that a three-factor solution would emerge within each emotion, with factors representing active, passive, and disruptive strategies (Grolnick et al., 1996; Silk et al., 2006).

A second goal of this research was to examine the complex links between shyness, fear regulation, and socio-emotional functioning. Accordingly, this research examined how fear regulation contributes to shy children's social adjustment in early childcare contexts. Given that early educational contexts can be particularly stressful for temperamentally shy and fearful children (Coplan et al., 2008; Dettling, Gunnar, \& Donzella, 1999), preschool childcare represents an opportunity to examine children's abilities to regulate fear and how it may relate to 
their early social adjustment. For example, it is possible that the negative social and behavioural consequences of shyness and subsequent fear dysregulation may be attenuated among very young children, as non-social forms of play are normative (Eggum-Wilkens et al., 2014). As social evaluative pressures intensify with age and peers become increasingly selective in their playmates, shyness may have gradually worse implications for children's social adjustment. A complex theoretical model was postulated, whereby fear regulation was expected to mediate associations between temperamental shyness and young children's socio-emotional functioning at preschool - and parental emotion socialization was hypothesized to moderate these associations (see Figure 1). In the current study, fear regulation was directly compared with anger regulation to determine the degree to which fear regulation uniquely contributes to the relations between shyness and social adjustment. Overall, it was expected that shyness would be associated with maladaptive regulation strategies in response to the expression of fear (but not anger). Consistent with previous research (Coplan et al., 2004a; Ladd, Kochenderfer-Ladd, Eggum, Kochel, \& McConnell, 2011), it was further hypothesized that shyness would be positively associated with indices of social adjustment difficulties (e.g., anxiety, peer exclusion).

Putting all of this together, it was hypothesized that fear regulation would mediate the association between shyness and indices of social adjustment. More specifically, temperamentally shy children were expected to have a higher reactivity toward social novelty and subsequently employ maladaptive regulatory strategies such as avoidance (e.g., Penela et al., 2015). In turn, these maladaptive fear regulation strategies were expected to predict socioemotional difficulties in the context of the early child education classroom (e.g., Blair et al., 2004). 


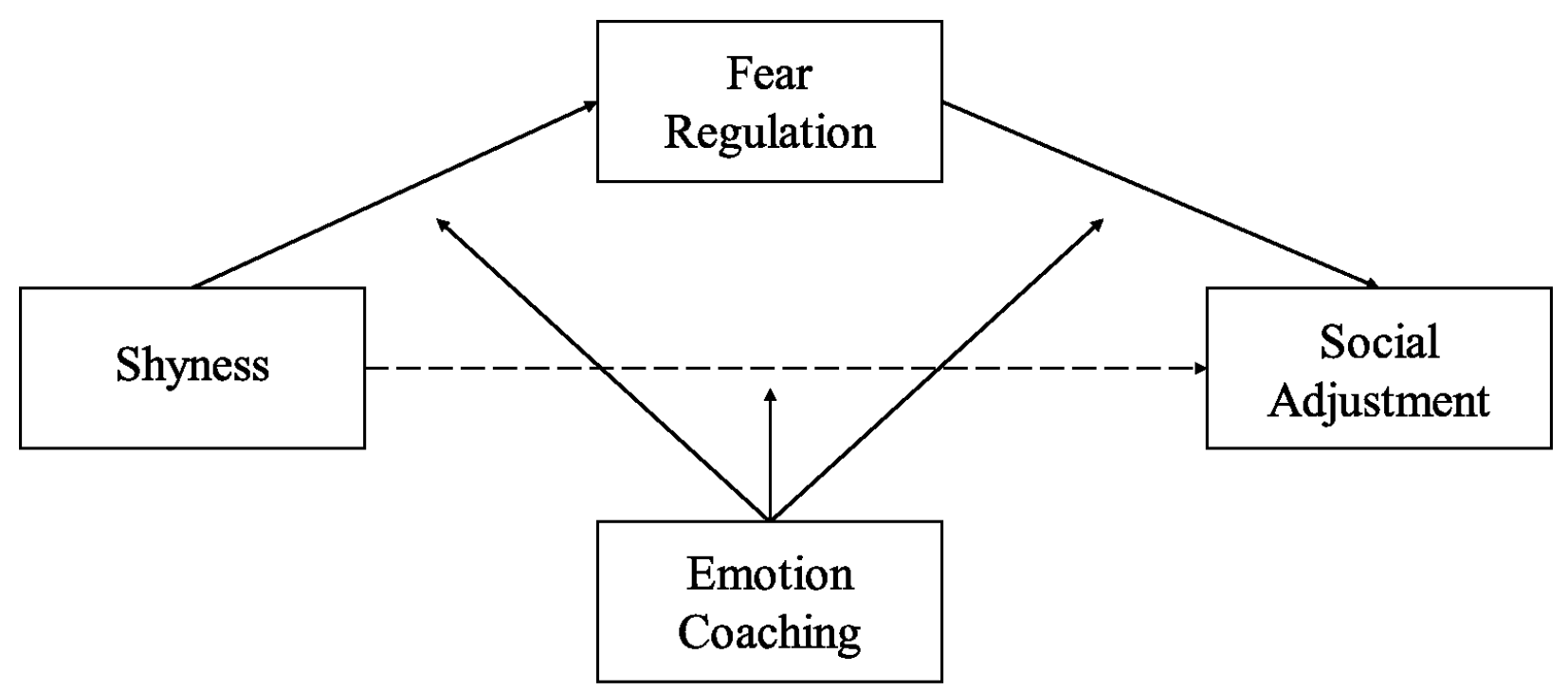

Figure 1. Hypothesized moderated-mediation model. The moderating role of parent emotion coaching was explored along three pathways: (1) from shyness to fear regulation; (2) from fear regulation to social adjustment; and (3) from shyness to social adjustment. 
Parental socialization of emotion was conceptualized as a moderator among the hypothesized associations in this model. Parental meta-emotion philosophy plays an important role in parents' reactions and responses toward children's emotional expressions. Emotion coaching parents implicitly model and explicitly teach their children proper ways of dealing with negative emotions (Gottman et al., 1996). As such, emotion coaching parenting may serve as a protective factor for children who are temperamentally at risk for social adjustment difficulties. For example, emotion coaching parents may be more likely to provide shy children with guidance for dealing with fear, which, in turn, could improve their subsequent social adjustment. Accordingly, in the present study the potential moderating role of parental emotion coaching was examined across multiple-pathways: (1) from shyness to fear regulation; (2) from fear regulation to adjustment; and (3) from shyness to adjustment (see Figure 1).

Finally, on a more exploratory basis, possible age and gender differences in this model were also be examined. Concerning age, previous research indicates that the relations between emotion regulation and social adjustment appear to strengthen with age, suggesting that as peer relations become more complex, the contextual demand for adaptive emotion regulation increases correspondingly (Spinrad et al., 2006). Developmental considerations of the relations between fear regulation and social adjustment remain unexplored; therefore, child age was explored as a moderator among the associations linking shyness to fear regulation and subsequent social adjustment.

Regarding gender, there is accumulating evidence to suggest that the consequences associated with shyness tend to vary as a function of child gender (Doey, Coplan, \& Kingsbury, 2014). Although there do not appear to be significant gender differences in the prevalence of shyness, the consequences associated with shyness appear to be more negative for boys (Colder, 
Mott, \& Berman, 2002; Coplan \& Weeks, 2009). This is believed to be the result of a societal gender bias, whereby shyness in boys is perceived as less socially acceptable compared to shyness in girls (Rubin \& Coplan, 2004). In short, shy behaviour in boys violates North American gender norms that characterize boys as stereotypically assertive and dominant. As a result, shy boys are perceived less favourably by peers and, in turn, experience greater degrees of peer victimization compared to shy girls whose behaviour aligns with societal expectations (Coplan et al., 2004a; Gazelle \& Ladd, 2003).

Similarly, there is also some evidence to suggest maladaptive emotion regulation is more strongly associated with social adjustment issues among boys than girls (Blair et al., 2004; Eisenberg et al., 1997; Herndon et al., 2013). This is particularly noteworthy given that, overall, boys are more likely than girls to use active emotion regulation strategies (Penela et al., 2015). Thus, boys' social adjustment may be more closely tied to individual differences in emotional competence. This may be, at least in part, due to a reporting bias, whereby boys must achieve a higher threshold of emotional competence in order to be viewed as socially adjusted as girls (Herndon et al., 2013). Nonetheless, previous studies have found no gender differences in the prevalence or consequences of fear dysregulation (Buss et al., 2011; 2013; 2017; Morales et al., 2014). It was accordingly hypothesized that gender would be a contributing factor with respect to anger regulation and not fear regulation. Overall, it was tentatively hypothesized that gender would moderate the associative pathways between shyness and social adjustment (stronger among boys than girls).

\section{Method}

\section{Participants}


Participants were $N=262$ children (137 boys) ranging from $2-5$ years of age $(M=3.23$ years, $S D=.51)$ attending 34 preschools and childcare centres scattered across two urban/suburban regions located in central/eastern and eastern Canada. There were $n=158$ $(60.3 \%)$ participants recruited from Site 1 (south-eastern Ontario) and $n=104(39.7 \%)$ recruited from Site 2 (central Nova Scotia). Two-hundred and two (77.1\%) parents identified as White/Caucasian, 22 (8.4\%) identified as Asian, 14 (5.3\%) as Black, $2(.8 \%)$ as Indigenous/Aboriginal, $1(.4 \%)$ as Hispanic, and $19(7.3 \%)$ as Other. Among mothers, 3 (1.1\%) reporting having not attended high school, 13 (5\%) completed high school, 47 (17.9\%) obtained a community college degree, $110(42 \%)$ received an undergraduate education, and $88(33.6 \%)$ had at least some graduate training. Among fathers, 6 (2.3\%) reporting having not attended high school, 29 (11.1\%) completed high school, 48 (18.3\%) obtained a community college degree, $102(38.9 \%)$ received an undergraduate education, and $69(26.3 \%)$ had at least some graduate training. 227 (86.6\%) of mothers were married/common law, $11(4.2 \%)$ were divorced/separated, and $20(7.6 \%)$ were single. From this sample, data from 14 participants ( 2 childcare centres) were removed from subsequent analyses because of late Time 1 data collection ${ }^{1}$, resulting in a final sample of $N=248\left(128\right.$ boys; $\left.M_{\text {age }}=3.22, S D=.51\right)$.

\section{Measures}

Multi-informant assessments were employed, including maternal and early childhood educator reports. All measures were previously deemed developmentally appropriate for use with young children.

Emotion regulation. Parents were asked to complete the 'fear' (13 items) and 'anger' (13 items) subscales of the Emotion Regulation Skills Questionnaire (ERSQ; Mirabile, 2014 -

\footnotetext{
${ }^{1}$ The two childcare centres that were removed from analyses did not begin data collection until January-February of 2017, which was deemed too late in accordance with the short-term longitudinal design.
} 
see Appendix A). This questionnaire asks parents to indicate the extent to which their child employs specific emotion regulation strategies when they are experiencing fear or anger. Individual items for each emotion probe specific regulatory behaviours, including more conceptually 'adaptive' strategies such as support seeking (reflecting the degree to which a child responds to an intense emotion by soliciting help of a caregiver), and 'maladaptive' strategies such as avoidance (reflecting the degree to which a child responds to an intense emotion by removing themselves from the emotion-eliciting stimulus). Importantly, this measure focuses on what children do when they are afraid or angry, as opposed to how children react to emotional stimuli. In this way, it was expected to capture the various emotion regulation strategies that children use during an emotional response.

Items are rated using a Likert-type scale ranging from 0 (never) to 4 (almost always). Sample items for the 'fear' subscale include "S/he shows his/her fear by crying, yelling, or screaming"; and for the 'anger' subscale include "S/he expresses his/her anger by banging, kicking, throwing things, or hitting things or people" (see Table 1 for all items). Mirabile (2014) aggregated these items on a conceptual basis to reflect children's use of 13 different regulatory strategies (e.g., constructive coping, support-seeking, distraction, etc.) across all emotions (anger, sadness, fear, happiness). This measure was adapted for the current study to separately assess and compare strategies for regulating fear and for regulating anger. Items pertaining to sadness and happiness were not conceptually relevant to the current study and were omitted to ease the burden on respondents. In its limited previous use, the two subscales demonstrated moderate internal reliability (Mirabile, 2014). Furthermore, the adaptive and maladaptive subscales demonstrated discriminant validity (i.e., negatively correlated), and were differentially associated 
with a validated measure of emotion regulation, the Emotion Regulation Checklist (ERC; Shields \& Cicchetti, 1997).

Shyness. Parents were asked to complete the Child Social Preference Scale (CSPS; Coplan, Prakash, O’Neil, \& Armer, 2004b - see Appendix B). Of particular interest for the present study was the subscale assessing children's shyness ( 7 items, e.g., "My child seems to want to play with other children, but is sometimes nervous to"). Items are rated using a Likerttype scale ranging from 1 (not at all) to 5 (a lot). In the current sample, these items demonstrated strong internal consistency $(a=.87)$. The CSPS has previously demonstrated satisfactory reliability and discriminant validity (Coplan et al., 2004b), and it converges with similar measures of shyness, such as behavioural inhibition and social anxiety (Dyson, Klein, Olino, Dougherty, \& Durbin, 2011).

Parental meta-emotion philosophy. Parents also completed the Maternal Emotional Styles Questionnaire (MESQ; Lagacé-Séguin \& Coplan, 2005 - see Appendix C). Items are rated using a Likert-type scale ranging from 1 (strongly disagree) to 5 (strongly agree). Of particular interest in the current study were the items pertaining to emotion coaching parenting ( 7 items, $a=.63$, e.g., "Anger is an emotion worth exploring"). This scale has previously demonstrated good convergent and construct validity, as evinced by congruence with traditional interview measures of meta-emotion philosophy and predictability of socio-emotional outcomes (Miller, Dunsmore, \& Smith, 2015).

Child social adjustment. Educators completed the Child Behavior Scale (CBS; Ladd \& Profilet, 1996 - see Appendix D). This scale includes a total of 35 items comprising six subscales to assess various aspects of children's social functioning: 'anxious with peers' (4 items; $a=.72$ ), 'excluded by peers' (7 items; $a=.85$ ), 'aggressive with peers' (7 items; $a=.88$ ) 
'asocial with peers' (6 items; $a=.87)$, 'prosocial with peers' ( 7 items; $a=.90)$, and 'hyperactivity' ( 4 items; $a=.85$ ). Items are rated using a Likert-type scale ranging from 1 (doesn't apply) to 3 (certainly applies). In a previous longitudinal assessment of the CBS, the scale demonstrated excellent convergent and predictive validity (Ladd, Herald-Brown, \& Andrews, 2009).

\section{Procedure}

The current study was designed as a 4-month short-term longitudinal study, involving data collection from parents during the Fall (Time 1: October-November) and subsequent data collection from early childhood educators during late-Winter/Spring (Time 2: March-April). After receiving REB approval at both sites, local childcare centres and preschools were contacted and invited (see Appendix E) during August-September to participate in the study. At Time 1, packages containing study information (see Appendix F), consent forms (see Appendix G), parent questionnaires (Demographics [see Appendix H], ERSQ, CSPS, \& MESQ), and debriefing (see Appendix I) were given to parents during end-of-day pick-up and returned in a sealed envelope to the childcare administrator upon completion.

CBS data was obtained from educators for 223 participants at Time 2 (15 children had withdrawn from the childcare centre prior to data collection at Time 2, and 4 questionnaires were not returned by educators). Researchers returned to the childcare centre and provided educators with packages containing study information (see Appendix J), consent forms (see Appendix K), debriefing (see Appendix L), and the CBS. Educators were asked to complete the CBS for children with whom they are most familiar. All participants were debriefed and informed that they could withdraw their data or participation at any point. Parents were not compensated for participation, however, participating childcare centres received a children's book donation. 


\section{Results}

\section{Overview}

Exploratory factor analysis of the ERSQ was conducted first to determine the subscales that would be used in subsequent analyses. Descriptive statistics for each variable were then computed and used to test assumptions of normality, linearity, and homoscedasticity. A series of ANOVAs was used to assess potential differences between groups based on age, gender, site, and other demographic variables (e.g., parent education level). Correlational analyses were then conducted to examine the relations among study variables. Lastly, a series of mediation and moderated-mediation analyses was conducted to explore the links between shyness, fear regulation, parental emotion socialization, and subsequent social adjustment. Child age and gender were also examined as moderators in these models.

\section{Factor Structure and Psychometric Properties of the ERSQ}

Previous research using the ERSQ had too limited a sample size to conduct a thorough validation of its theorized factor structure (Mirabile, 2014). Accordingly, one of the goals of this research was to explore the factor structure and psychometric properties of the ERSQ items pertaining to anger and fear. Descriptive statistics for the individual items are displayed in Table 1. Results indicated that the 'Suppression' item pertaining to the regulation of both anger and fear demonstrated excessive skewness (i.e., $>|1|$ ) and low variability. Thus, this item was omitted from further analyses. As well, the item 'Aggression' as a form of fear regulation was also dropped for demonstrating inadequate skewness and kurtosis. 
Table 1

Descriptive Statistics for Individual ERSQ Items

\begin{tabular}{|c|c|c|c|c|c|c|}
\hline Item (abbreviated) & Min. & Max. & $M$ & $S D$ & Skewness & Kurtosis \\
\hline \multicolumn{7}{|l|}{ Anger } \\
\hline Self-directed speech & .00 & 4.00 & 1.26 & 1.00 & .41 & -.47 \\
\hline Constructive/instrumental coping & .00 & 4.00 & 2.67 & .95 & -.27 & -.45 \\
\hline Information gathering & .00 & 4.00 & 2.62 & 1.20 & -.58 & -51 \\
\hline Focusing on distressing object & .00 & 4.00 & 2.06 & 1.17 & -.03 & -.87 \\
\hline Venting & .00 & 4.00 & 3.03 & .89 & -.56 & -.36 \\
\hline Aggression & .00 & 4.00 & 1.84 & 1.16 & .24 & -.69 \\
\hline Verbal/other-oriented distraction & .00 & 4.00 & .87 & .90 & .86 & .29 \\
\hline Self/object-oriented distraction & .00 & 4.00 & 1.44 & .96 & .11 & -.45 \\
\hline Self-comforting/soothing & .00 & 4.00 & 1.25 & 1.28 & .73 & -.59 \\
\hline Comfort seeking & .00 & 4.00 & 2.85 & .97 & -.56 & -.24 \\
\hline Support seeking & .00 & 4.00 & 2.53 & 1.04 & -.47 & -.35 \\
\hline Avoidance & .00 & 4.00 & 1.32 & 1.11 & .37 & -.52 \\
\hline Suppression & .00 & 3.00 & .56 & .71 & 1.14 & .88 \\
\hline \multicolumn{7}{|l|}{ Fear } \\
\hline Self-directed speech & .00 & 4.00 & 1.34 & .98 & .37 & -.74 \\
\hline Constructive/instrumental coping & .00 & 4.00 & 1.76 & .94 & .06 & -.25 \\
\hline Information gathering & .00 & 4.00 & 2.29 & 1.23 & -.31 & -.83 \\
\hline Focusing on distressing object & .00 & 4.00 & 1.86 & 1.09 & .13 & -.64 \\
\hline Venting & .00 & 4.00 & 2.05 & 1.21 & -.00 & -.83 \\
\hline Aggression & .00 & 3.00 & .46 & .72 & 1.51 & 1.73 \\
\hline Verbal/other-oriented distraction & .00 & 4.00 & .97 & .89 & .53 & -.42 \\
\hline Self/object-oriented distraction & .00 & 4.00 & 1.23 & 1.04 & .45 & -.61 \\
\hline Self-comforting/soothing & .00 & 4.00 & 1.28 & 1.25 & .68 & -.64 \\
\hline Comfort seeking & .00 & 4.00 & 3.46 & .75 & -1.58 & 3.20 \\
\hline Support seeking & .00 & 4.00 & 3.27 & .86 & -1.34 & 2.24 \\
\hline Avoidance & .00 & 4.00 & 2.34 & 1.09 & -.14 & -.65 \\
\hline Suppression & .00 & 4.00 & .59 & .78 & 1.34 & 1.74 \\
\hline
\end{tabular}


Next, separate exploratory principal components analyses were conducted for the ERSQ items pertaining to regulation of anger versus fear. For the anger items, a four-factor solution was initially indicated (i.e., four factors with Eigenvalues $>1$ ). However, there were two instances of items cross-loading (i.e., > .30) on more than one factor. These items ('Self-directed speech'; 'Self-comforting') were then omitted the analysis was repeated. The final solution was comprised of 3 factors (see Table 2). The first factor was labelled Dysregulation and accounted for $26.04 \%$ of the variance (Eigenvalue $=2.60$; Cronbach's $a=.69$ ). The second factor appeared to assess items related to distraction, and accounted for $17.48 \%$ of the variance (Eigenvalue $=$ 1.75; Cronbach's $a=.57)$. However, two of the three items for this scale also cross-loaded (above .30 ) on Factor 1. The third factor included items that seemed to pertain somewhat to the strategy of support and accounted for $12.31 \%$ of the variance (Eigenvalue $=1.23$; Cronbach's $a$ $=.48$ ). Given the issues with these two latter factors (cross-loading items, lack of cohesive theoretical structure, poor internal consistency), they were dropped from subsequent analyses. Factor 1 was retained as an index of anger dysregulation.

For the fear items, a four-factor solution was also initially suggested. There were, however, two instances of items cross-loading (i.e., > .30) on more than one factor. These items ('Venting'; 'Focusing on distressing object') were dropped and the analysis was repeated. The remaining 9 items were re-analyzed, revealing a final solution comprised of 3 factors (see Table 3). The first factor was labelled Active and accounted for $25.33 \%$ of the variance (Eigenvalue $=$ 2.28; Cronbach's $a=.70$ ). The second factor appeared to assess items related to distraction, and accounted for $20.21 \%$ of the variance (Eigenvalue $=1.82$; Cronbach's $a=.49$ ) However, one of three items for this scale also cross-loaded (above .30) on Factor 3. The third factor contained two items related to seeking comfort and support, and one pertaining to avoidance, and 
accounted for $15.14 \%$ of the variance (Eigenvalue $=1.36$; Cronbach's $a=.58$ ). As previously, given the issues with these two latter factors (cross-loading item, lack of cohesive theoretical structure, poor internal consistency), they were dropped from subsequent analyses. Factor 1 was retained and labelled as an index of active fear regulation.

In summary, factor analysis of ERSQ items pertaining to fear and anger regulation identified conceptually interpretable and internally reliable composites representing active fear regulation ( 3 items; $a=.70$ ) and anger dysregulation ( 4 items; $a=.69$ ). To ease presentation, in subsequent analyses 'active fear regulation' is henceforth referred to as just 'fear regulation'. Although the items in the active fear regulation items address different strategies from those in the anger dysregulation items, these indices were assessed comparatively to address whether fear regulation would be a more salient predictor of shyness and its associations with social adjustment. 
Table 2

Factor Loadings for ERSQ Anger Items

Factor and Item (abbreviated) Factor Loadings

I II III

\section{Factor I: Dysregulation}

Constructive/instrumental coping .75

Focusing on distressing object

Venting .70

Aggression

\section{Factor II}

Verbal/other-oriented distraction

Self/object-oriented distraction

$-.39$

.74

Avoidance

\section{Factor III}

Information gathering

Comfort seeking

Support seeking

Note: only factor loadings $>.30$ are displayed 
Table 3

Factor Loadings for ERSQ Fear Items

Factor and Item (abbreviated) Factor Loadings

I II III

\section{Factor I: Active}

Self-directed speech

.82

Constructive/instrumental coping

.73

Information gathering

.76

\section{Factor II}

Verbal/other-oriented distraction .86

Self/object-oriented distraction .79

Self-comforting/soothing

Factor III

Comfort seeking

Support seeking

Avoidance

.62

Note: only factor loadings $>.30$ are displayed 


\section{Preliminary Analyses}

Descriptive statistics for all study variables are summarized in Table 4. Skewness and kurtosis were assessed for each variable of interest to test the assumption of normality. Data obtained from parents (shyness, emotion regulation, emotion socialization) all had appropriate skewness and kurtosis. Among the variables obtained from educators, exclusion and aggression were found to be highly non-normal (skewness $>|1|$; kurtosis $>|3|$ ) and asocial behaviour was found to be moderately positively skewed. Roughly $10 \%$ of participants were missing data on educator-rated outcomes due to attrition and unreturned questionnaires. Missing data was analyzed with Little's MCAR test, which was not significant: $\chi^{2}=123.281(d f=108, p=.150)$, indicating that the data is missing at random and is likely not attributable to systematic variation among study variables.

Results from $\chi^{2}$ analyses indicated that the proportion of younger (i.e., aged 3 years and below) and older (i.e., aged 4 years and above) children differed significantly between the Ottawa and Halifax samples $\left(\chi^{2}=63.46, p<.001\right)$ - with the Halifax sample comprised of a greater proportion of older children and the Ottawa sample including a greater proportion of younger children. This age discrepancy is attributable to differences in school board policies between the two sites, where in Ottawa children are introduced to full-day formal education one year earlier compared to those in Halifax. Apart from age, there were no significant differences between sites in the proportion of boys vs. girls, parental education, or ethnicity.

To examine main effects of child gender (boy, girl) and age (younger, older), a series of 2 x 2 ANOVAs was conducted for each of the main study variables. Results indicated significant main effects of child age for anger dysregulation, $F(1,241)=6.162, p=.014$, with younger children $(M=2.467, S D=.759)$ rated as demonstrating greater anger dysregulation than older children $(M=2.189, S D=.693)$, and educator-rated aggression, $F(1,219)=5.970, p=.015$, 
with older children scoring higher on aggression $(M=1.465, S D=.507)$ than younger children $(M=1.310, S D=.391)$.

Significant gender differences were also observed. Results indicated significant main effects of gender for educator-rated anxious behaviors, $F(1,219)=4.960, p=.027$, with boys $(M$ $=1.502, S D=.520)$ rated as more anxious than girls $(M=1.362, S D=.396)$; peer exclusion, $F(1,219)=7.190, p=.008$, with boys $(M=1.228, S D=.342)$ rated as more excluded than girls $(M=1.098, S D=.220)$; aggression, $F(1,219)=4.60, p=.033$, with boys $(M=1.432, S D=$ .486) rated as more aggressive compared to girls $(M=1.270, S D=.346)$; asocial behaviour, $F(1$, $219)=5.13, p=.025$, with boys $(M=1.448, S D=.508)$ rated as more asocial than girls $(M=$ $1.269, S D=.319)$; hyperactivity, $F(1,219)=6.755, p=.010$, with boys $(M=1.638, S D=.589)$ rated as more hyperactive than girls $(M=1.411, S D=.543)$; and prosocial behaviour, $F(1,219)$ $=9.970, p=.002$, with girls $(M=2.536, S D=.423)$ rated as more prosocial than boys $(M=$ $2.245, S D=.569)$. Accordingly, child age and gender were controlled for in subsequent analyses. A composite parental education score was computed by aggregating maternal and paternal education levels. When controlling for age and gender, parental education was significantly and negatively associated with educator-rated aggression $(r=-.282, p<.001)$, asocial behaviour $(r=-.138, p=.043)$, and hyperactivity $(r=-.214, p=.002)$. Relations between parental education and anger dysregulation $(r=-.118, p=.065)$, peer exclusion $(r=$ $.132, p=.053)$, and prosocial behaviour $(r=.131, p=.054)$ all approached significance. Parental education was thus also controlled for in subsequent analyses. 
Table 4

Descriptive Statistics for all Study Variables

\begin{tabular}{lccccccc}
\hline \multicolumn{1}{c}{ Variable } & Min. & Max. & Scale & $M$ & $S D$ & Skewness & Kurtosis \\
\hline Demographics & & & & & & & \\
$\quad$ Parent education & 1.00 & 5.00 & $1-5$ & 3.89 & .87 & -.87 & .17 \\
Child age (years) & 2.00 & 5.00 & - & 3.22 & .51 & .66 & .79 \\
Parent-rated (Time 1: Fall) & & & & & & & \\
Shyness & 1.00 & 4.86 & $1-5$ & 2.26 & .80 & .48 & -.33 \\
Fear regulation & .00 & 4.00 & $0-4$ & 1.80 & .87 & .14 & -.46 \\
Anger dysregulation & .50 & 4.00 & $0-4$ & 2.40 & .75 & .00 & -.59 \\
Emotion coaching & 2.57 & 5.00 & $1-5$ & 3.89 & .47 & .04 & -.21 \\
Educator-rated (Time 2: Spring) & & & & & & & .45 \\
Anxiety with peers & 1.00 & 3.00 & $1-3$ & 1.43 & .47 & 1.06 & 3.70 \\
Excluded by peers & 1.00 & 2.14 & $1-3$ & 1.16 & .29 & 2.11 & 3.16 \\
Aggressive behaviour & 1.00 & 3.00 & $1-3$ & 1.35 & .43 & 1.79 & -.43 \\
Prosocial behaviour & 1.00 & 3.00 & $1-3$ & 2.39 & .52 & -.62 & 2.08 \\
Asocial behaviour & 1.00 & 3.00 & $1-3$ & 1.36 & .43 & 1.54 & -.21 \\
Hyperactivity & 1.00 & 3.00 & $1-3$ & 1.52 & .58 & .93 & \\
\hline
\end{tabular}




\section{Correlations among Study Variables}

Table 5 summarizes the correlations among study variables. Of note, fear regulation was significantly and negatively associated with shyness and positively associated with parental emotion coaching. The negative association between fear regulation and educator-rated asocial behaviour approached significance. Taken together, these associations provide some preliminary evidence of the validity of this newly derived subscale.

In contrast, anger dysregulation was significantly and negatively associated with fear regulation, but otherwise not significantly associated with any other child or parent characteristics, or educator ratings. Thus, there was very limited evidence of validity for this subscale.

Shyness was marginally negatively correlated with parental emotion coaching. For educator-rated outcomes, shyness negatively predicted aggression and positively predicted asocial behaviour. Parental emotion coaching was associated with greater fear regulation and less shyness, and approached significance in positively predicting hyperactivity. 
Table 5

Partial Correlations among Study Variables (Controlling for Age, Gender, and Parental Education)

\begin{tabular}{|c|c|c|c|c|c|c|c|c|c|}
\hline & 2 & 3 & 4 & 5 & 6 & 7 & 8 & 9 & 10 \\
\hline $\begin{array}{l}1: \text { Shyness } \\
n=248\end{array}$ & $-.271 * * *$ & .050 & $-.123^{\dagger}$ & .105 & -.086 & $-.209 * *$ & .086 & $.173 *$ & $-.119^{\dagger}$ \\
\hline $\begin{array}{l}2: \text { Fear Regulation } \\
n=248\end{array}$ & - & $-.213 * *$ & $.145^{*}$ & -.059 & .062 & -.056 & .092 & $-.121^{\dagger}$ & .009 \\
\hline $\begin{array}{l}\text { 3: Anger Dysregulation } \\
n=248\end{array}$ & & - & -.011 & .037 & .006 & .081 & -.095 & -.017 & .082 \\
\hline $\begin{array}{l}\text { 4: Parental Coaching } \\
n=248\end{array}$ & & & - & .009 & .027 & .034 & .041 & -.050 & $.120^{\dagger}$ \\
\hline $\begin{array}{l}\text { 5: Anxious with Peers } \\
n=223\end{array}$ & & & & - & $.256^{* * *}$ & -.085 & $-.204 * *$ & $.534 * * *$ & .067 \\
\hline $\begin{array}{l}\text { 6: Excluded by Peers } \\
n=223\end{array}$ & & & & & - & $.412 * * *$ & $-.551 * * *$ & $.443 * * *$ & $.398 * * *$ \\
\hline $\begin{array}{l}\text { 7: Aggression } \\
n=223\end{array}$ & & & & & & - & $-.345 * * *$ & -.085 & $.401 * * *$ \\
\hline $\begin{array}{l}8: \text { Prosocial } \\
n=223\end{array}$ & & & & & & & - & $-.408 * * *$ & $-.382 * * *$ \\
\hline $\begin{array}{l}\text { 9: Asocial } \\
n=223\end{array}$ & & & & & & & & - & .081 \\
\hline $\begin{array}{l}\text { 10: Hyperactivity } \\
n=223\end{array}$ & & & & & & & & & - \\
\hline
\end{tabular}

$* * * p<.001 \quad * * p<.01 \quad * p<.05 \quad \dagger p<.10$ 


\section{Mediation and Moderated-Mediation Analyses}

It was hypothesized that fear regulation would mediate the links between shyness and indices of social adjustment. It was further hypothesized that parental emotion coaching would moderate the mediated pathways linking shyness to fear regulation and subsequent social adjustment. Moderating effects of child characteristics, including gender and age, were also explored. Accordingly, a series of mediation and moderated-mediation models was tested, with shyness indirectly predicting each of the relevant outcomes variables (anxiety, peer exclusion, prosocial behaviour, and asocial behaviour) through a mediation of fear regulation, and moderated by parental emotion coaching, child age and gender (see Figure 1). The PROCESS macro (Hayes, 2016) was used to run the mediation and moderated-mediation analyses with 5000 bootstrap samples.

Anxiety. As indicated in Table 6, the mediation model predicting anxious behaviours was not statistically significant. Shyness did not directly predict anxious behaviours, and fear regulation did not significantly mediate the association between shyness and anxiety. Moreover, emotion coaching did not significantly moderate the pathways linking shyness to fear regulation, fear regulation to anxiety, or shyness to anxiety. Lastly, child gender and age were examined as moderators within the models predicting anxiety, but were also not significant.

Peer exclusion. As with the previous results, shyness also did not directly predict peer exclusion and fear regulation was not a significant mediator (see Table 7). Parental emotion coaching did not significantly moderate the pathways linking fear regulation to peer exclusion or shyness to peer exclusion. Gender also did not significantly moderate these pathways.

Lastly, age did not significantly moderate the pathways linking fear regulation to peer exclusion or shyness to peer exclusion. However, looking at the conditional direct effects among shyness and peer exclusion compared between age groups, shyness was found to (marginally) 
negatively predict peer exclusion among younger children: $\beta=-.148, S E=.083, p=.078$, yet not among older children: $\beta=.063, S E=.132, p=.633$. The index of moderated-mediation indicated that these effects were not significantly different as the confidence interval includes 0: $\beta=.067$, $S E=.072,95 \% \mathrm{CI}=-.056-.233$.

Prosocial behaviour. For prosocial behavior (see Table 8), shyness was not a direct predictor, however, fear regulation approached significance as a mediator. This trend suggests that fear regulation may play a minor role in mediating the negative association between shyness and prosocial behaviour. The effect of this trending mediation is small, with the negative association between shyness and fear regulation accounting for a 3\% decrease in prosocial behaviour. Neither emotion coaching nor gender were significant moderators in the models predicting prosocial behaviour.

However, child age was found to significantly moderate the mediated pathway from fear regulation to shyness to prosocial behaviour (see Figure 2). Specifically, age moderated the pathway linking fear regulation to prosocial behaviour, whereby fear regulation more strongly predicted prosocial behaviour among older children compared to younger children. Comparing the conditional indirect effects of shyness on prosocial behaviour via fear regulation for each age group, fear regulation only mediated the association between shyness and prosocial behaviour among children aged 4 years and older: $\beta=-.158, S E=.079,95 \% \mathrm{CI}=-.357--.038$, and not among children aged 3 years and below: $\beta=-.007, S E=.019,95 \% \mathrm{CI}=-.052-.027$. The index of moderated-mediation, which tests the difference between the conditional effects at each level of the moderator, indicated that these effects are statistically significant, with the bootstrapped confidence interval not containing $0: \beta=-.151, S E=.081,95 \% \mathrm{CI}=-.350--.026$. In other 
words, this result suggests that, among older shy preschoolers, less active fear regulation significantly predicts less prosocial behaviour, but not among younger shy preschoolers.

Asocial behaviour. Lastly, shyness significantly positively predicted asocial behaviour, but was not mediated by fear regulation (see Table 9). Emotion coaching and gender again did not moderate the pathways linking shyness and fear regulation to asocial behaviour. The moderating effect of child age approached significance in the direct association between shyness and asocial behaviour: $\beta=.284, S E=.155, p=.068$. This trend indicated that, among older children, shyness positively predicted asocial behaviour: $\beta=.356, S E=.132, p=.007$, yet not among younger children: $\beta=.072, S E=.082, p=.381$; however, the difference between these effects was marginally significant. 
Table 6

Mediation and Moderated-Mediation Models Predicting Anxious Behaviours

$\begin{array}{lllllll}\text { Model } & R^{2} & \beta & S E & p & 95 \% \text { LCI } & 95 \% \text { UCI }\end{array}$

\begin{tabular}{|c|c|c|c|c|c|c|}
\hline Anxiety & & & & & & \\
\hline Mediation: Shy $\rightarrow F R \rightarrow$ Anx & .037 & & & & & \\
\hline Direct effect: Shy $\rightarrow$ Anx & & .084 & .071 & .233 & -.055 & .224 \\
\hline Indirect effect: Shy $\rightarrow$ FR $\rightarrow$ Anx & & .009 & .019 & ns & -.027 & .050 \\
\hline Moderated-mediation: Emotion coaching & .040 & & & & & \\
\hline Shy X EC $\rightarrow \mathrm{FR}^{\mathrm{a}}$ & & -.063 & .072 & .383 & -.205 & .079 \\
\hline $\mathrm{FR} X \mathrm{EC} \rightarrow \mathrm{Anx}$ & & -.021 & .071 & .774 & -.161 & .120 \\
\hline Shy $X$ EC $\rightarrow$ Anx & & -.045 & .077 & .560 & -.197 & .107 \\
\hline Moderated-mediation: Gender & .049 & & & & & \\
\hline Shy X Gender $\rightarrow$ FR $^{\mathrm{b}}$ & & -.192 & .132 & .147 & -.452 & .068 \\
\hline FR X Gender $\rightarrow$ Anx & & .182 & .140 & .196 & -.095 & .458 \\
\hline Shy X Gender $\rightarrow$ Anx & & -.078 & .142 & .587 & -.358 & .203 \\
\hline Moderated-mediation: Age & .051 & & & & & \\
\hline Shy X Age $\rightarrow \mathrm{FR}^{\mathrm{c}}$ & & -.153 & .142 & .283 & -.433 & .127 \\
\hline FR $X$ Age $\rightarrow$ Anx & & -.006 & .173 & .973 & -.347 & .336 \\
\hline Shy $X$ Age $\rightarrow$ Anx & & .258 & .158 & .103 & -.053 & .568 \\
\hline
\end{tabular}

$* * * p<.001 \quad * * p<.01 \quad * p<.05 \quad \dagger p<.10$.

Analyses controlled for gender, age, and parental education. For mediation models, direct effect denotes the association between shyness and the outcome variable while controlling for the mediator. Indirect effect indicates the association between shyness and the outcome variable mediated by fear regulation. Of note, testing the indirect effect does not provide a $p$-value as indication of significance, rather, significance is evidenced by the bootstrapped $95 \%$ confidence interval not including $0 . \mathrm{FR}=$ Fear Regulation; $\mathrm{EC}=$ Emotion Coaching; Anx = Anxious Behaviours.

a, b, c Coefficients predicting fear regulation are identical across models for all indices of social adjustment, and are thus presented here only. 
Table 7

Mediation and Moderated-Mediation Models Predicting Peer Exclusion

$\begin{array}{lllllll}\text { Model } & R^{2} & \beta & S E & p & 95 \% \text { LCI } & 95 \% \text { UCI }\end{array}$

\section{Peer exclusion}

Mediation: Shy $\rightarrow F R \rightarrow$ Exc

.074

Direct effect: Shy $\rightarrow$ Exc

Indirect effect: Shy $\rightarrow$ FR $\rightarrow$ Exc

$\begin{array}{llll}-.069 & .070 & .330 & -.207\end{array}$

.070

Moderated-mediation: Emotion coaching

FR X EC $\rightarrow$ Exc

$\begin{array}{llll}.011 & .023 & \text { ns } & -.059\end{array}$

.079

Shy $\mathrm{X} \mathrm{EC} \rightarrow$ Exc

$\begin{array}{lllll}.026 & .071 & .716 & -.114 & .166 \\ .056 & .077 & .466 & -.095 & .207\end{array}$

Moderated-mediation: Gender

.085

FR X Gender $\rightarrow$ Exc

$\begin{array}{llll}.212 & .139 & .128 & -.062 \\ .075 & .142 & .596 & -.204\end{array}$

Shy X Gender $\rightarrow$ Exc .097

Moderated-mediation: Age

FR X Age $\rightarrow$ Exc

$-.214 \quad .171 \quad .213 \quad-.551$

Shy $X$ Age $\rightarrow$ Exc

$\begin{array}{llll}.211 & .156 & .176 & -.095\end{array}$

$* * * p<.001 \quad * * p<.01 \quad * p<.05 \quad \dagger p<.10$.

Analyses controlled for gender, age, and parental education. For mediation models, direct effect denotes the association between shyness and the outcome variable while controlling for the mediator. Indirect effect indicates the association between shyness and the outcome variable mediated by fear regulation. Of note, testing the indirect effect does not provide a $p$-value as indication of significance, rather, significance is evidenced by the bootstrapped $95 \%$ confidence interval not including $0 . \mathrm{FR}=$ Fear Regulation; EC = Emotion Coaching; Exc $=$ Peer Exclusion. 
Table 8

Mediation and Moderated-Mediation Models Predicting Prosocial Behaviour

$\begin{array}{lllllll}\text { Model } & R^{2} & \beta & S E & p & 95 \% \text { LCI } & 95 \% \text { UCI }\end{array}$

\section{Prosocial}

Mediation: Shy $\rightarrow F R \rightarrow$ Pro

.114

Direct effect: Shy $\rightarrow$ Pro

$\begin{array}{lllll}.107 \quad .068 \quad .028 & .06 & .02\end{array}$

Indirect effect: Shy $\rightarrow$ FR $\rightarrow$ Pro

$-.032 \quad .022$

.006

Moderated-mediation: Emotion coaching

.122

FR X EC $\rightarrow$ Pro

$\begin{array}{llll}.041 & .069 & .549 & -.094 \\ .045 & .074 & .544 & -.101\end{array}$

Shy X EC $\rightarrow$ Pro

.120

Moderated-mediation: Gender

$\begin{array}{rrrr}-.090 & .136 & .509 & -.358 \\ .109 & .138 & .433 & -.164\end{array}$

FR X Gender $\rightarrow$ Pro

Shy X Gender $\rightarrow$ Pro .136

Moderated-mediation: Age

FR X Age $\rightarrow$ Pro

\begin{tabular}{rrrr}
.385 & .167 & $.022 *$ & .056 \\
.066 & .152 & .663 & -.232 \\
\hline
\end{tabular}

Shy $\mathrm{X}$ Age $\rightarrow$ Pro

.365

$* * * p<.001 \quad * * p<.01 \quad * p<.05 \quad \dagger p<.10$.

Analyses controlled for gender, age, and parental education. For mediation models, direct effect denotes the association between shyness and the outcome variable while controlling for the mediator. Indirect effect indicates the association between shyness and the outcome variable mediated by fear regulation. Of note, testing the indirect effect does not provide a $p$-value as indication of significance, rather, significance is evidenced by the bootstrapped $95 \%$ confidence interval not including $0 . \mathrm{FR}=$ Fear Regulation; EC = Emotion Coaching; Pro = Prosocial Behaviour 
Table 9

Mediation and Moderated-Mediation Models Predicting Asocial Behaviour

\begin{tabular}{|c|c|c|c|c|c|c|}
\hline Model & $R^{2}$ & $\beta$ & $S E$ & $p$ & $95 \% \mathrm{LCI}$ & $95 \% \mathrm{UCI}$ \\
\hline \multicolumn{7}{|l|}{ Asocial } \\
\hline Mediation: Shy $\rightarrow F R \rightarrow$ Asoc & .088 & & & & & \\
\hline Direct effect: Shy $\rightarrow$ Asoc & & .150 & .070 & $.032 *$ & .013 & .287 \\
\hline Indirect effect: Shy $\rightarrow$ FR $\rightarrow$ Asoc & & .018 & .018 & ns & -.013 & .061 \\
\hline Moderated-mediation: Emotion coaching & .089 & & & & & \\
\hline FR X EC $\rightarrow$ Asoc & & .001 & .071 & .990 & -.138 & .140 \\
\hline Shy X EC $\rightarrow$ Asoc & & .030 & .076 & .696 & -.120 & .180 \\
\hline Moderated-mediation: Gender & .096 & & & & & \\
\hline FR X Gender $\rightarrow$ Asoc & & .147 & .138 & .289 & -.125 & .419 \\
\hline Shy X Gender $\rightarrow$ Asoc & & -.070 & .140 & .618 & -.347 & .207 \\
\hline Moderated-mediation: Age & .102 & & & & & \\
\hline FR X Age $\rightarrow$ Asoc & & .140 & .170 & .411 & -.195 & .476 \\
\hline Shy X Age $\rightarrow$ Asoc & & .284 & .155 & $.068 \dagger$ & -.021 & .589 \\
\hline
\end{tabular}

$* * * p<.001 \quad * * p<.01 \quad * p<.05 \quad \dagger p<.10$.

Analyses controlled for gender, age, and parental education. For mediation models, direct effect denotes the association between shyness and the outcome variable while controlling for the mediator. Indirect effect indicates the association between shyness and the outcome variable mediated by fear regulation. Of note, testing the indirect effect does not provide a $p$-value as indication of significance, rather, significance is evidenced by the bootstrapped $95 \%$ confidence interval not including 0 . FR $=$ Fear Regulation; EC = Emotion Coaching; Asoc = Asocial Behaviour. 


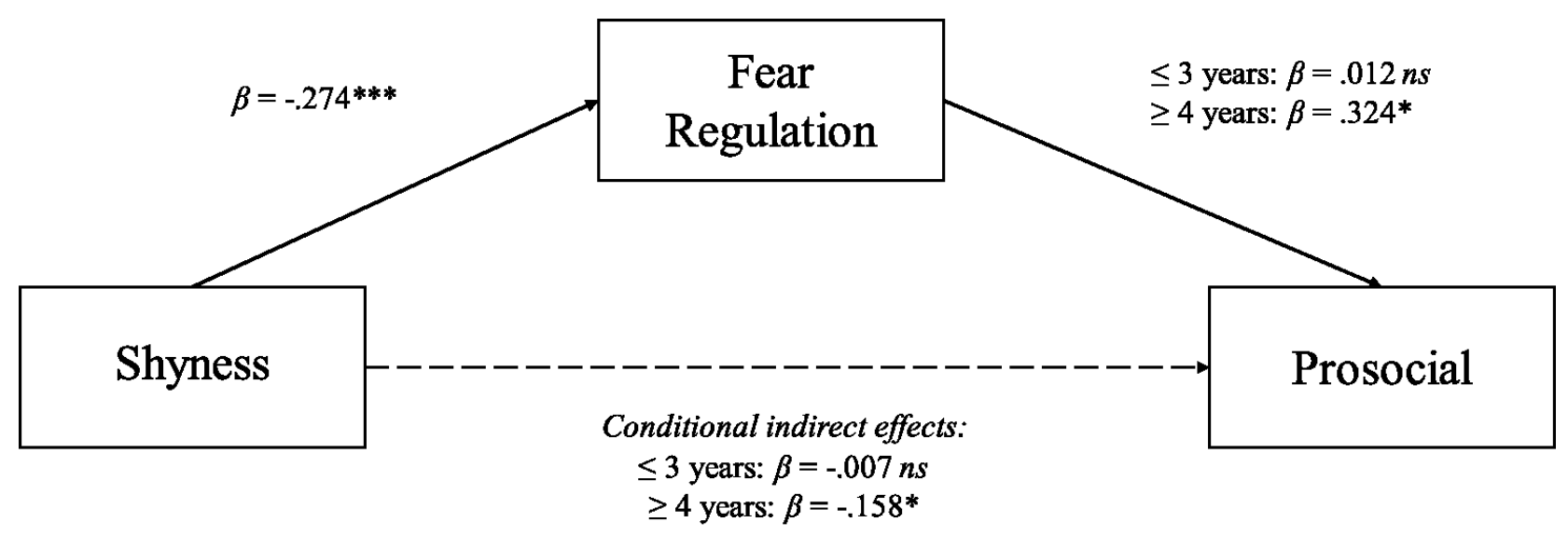

Figure 2. Moderated-mediation model of shyness predicting prosocial behaviour mediated by fear regulation, conditional on child age.

Note: Age moderation is significant in the pathway linking fear regulation to prosocial behaviour. Conditional indirect effects represent the overall effect of shyness on prosocial behaviour as mediated by fear regulation at each age group. 


\section{Discussion}

Optimal social and emotional development in young children is largely predicated on the ability to regulate emotions (Rothbart \& Bates, 2006). Previous research has highlighted the role of emotion regulation in shy children's socio-emotional development, revealing that shy children tend to employ more maladaptive and fewer adaptive strategies for dealing with emotions, which, in turn, negatively impacts social adjustment (Feng et al., 2011; Penela et al., 2015). However, researchers have predominately focused on children's ability to regulate anger and frustration, when, with respect to shyness, it may be conceptually more appropriate to consider fear regulation. A recently developed measure of emotion regulation was adapted for the current study to assess children's strategies for regulating fear and anger. Fear regulation was then assessed as a mechanism linking shyness and subsequent social adjustment within preschool childcares. Parental emotion socialization, specifically parents' emotion coaching, was further examined as a moderator among these associations, as well as child characteristics including age and gender.

Overall, there was marginal support for the hypothesis that fear regulation would mediate associations between shyness and social adjustment four months later. As expected, shyness was significantly negatively associated with fear regulation and not significantly associated with anger regulation, providing further evidence for the importance of considering emotion-specific regulation. In contrast, however, fear regulation did not directly predict indices of social adjustment four months later and shyness only predicted greater asocial behaviour. The primary hypothesis, that fear regulation would mediate the association between shyness and indices of social adjustment, was not initially supported. Furthermore, neither parental emotion coaching nor child gender moderated these associations. 
However, somewhat unexpectedly, age was found to significantly moderate the association between fear regulation and prosocial behaviour, and consequently, was a moderator in the mediation model linking shyness to fear regulation and subsequent prosocial behaviour. There was also some evidence indicating that shyness was more strongly associated with asocial behaviour in older children, and that the relation between shyness and peer exclusion increased from a negative to a positive relation with age. Findings are discussed in detail in the proceeding sections, beginning with the results from the factor analysis of the ERSQ, followed by the findings pertaining to children's social adjustment, as well as age-related differences. Finally, this section concludes with implications, future directions, and conclusions.

\section{Measurement of Fear and Anger Regulation in Young Children}

Compared to anger regulation, fear regulation has been largely overlooked as a predictor of children's social adjustment. Although previous research has examined young children's expression of fear over a variety of observational contexts (Buss et al., 2011; 2013; 2017), no studies have yet assessed preschool children's fear regulation strategies. One objective of the current research was to inspect the psychometric properties of a newly adapted parent-report measure designed to assess preschoolers' use of fear regulation strategies (Mirabile, 2014). The ERSQ was originally designed to measure children's global emotion regulation (i.e., combined across the four emotions of anger, sadness, fear, and happiness), but was adapted for the current study to examine the individual emotions of anger and fear. In Mirabile's implementation of the ERSQ, the strategies were grouped a priori as either adaptive or maladaptive based on theory and previous empirical work (e.g., Calkins et al., 1999; Grolnick et al., 1996). In this earlier research (Mirabile, 2014), low sample size $(n<100)$ prevented conducting a factor analysis to 
thoroughly validate these purported subscales. The current study addressed this issue by using a large enough sample size to explore the underlying factor solution of the ERSQ.

The conceptually derived factor structure postulated by Mirabile (2014) implied that items pertaining to anger and fear each be found to have two-factor solutions representing adaptive and maladaptive strategies. In the current study, however, it was hypothesized that fear and anger would be found to have three-factor solutions representing active, passive, and disruptive strategies (Grolnick et al., 1996; Silk et al., 2006). Consistent with this expectation, after eliminating problematic items, three-factor solutions were initially revealed for both anger and fear. However, subsequent analysis of the content, cross-loadings, and internal consistency of each factor revealed only two tenable subscales, representing fear regulation and anger dysregulation. Interestingly, these results did not align with the theory-derived 'adaptive' and 'maladaptive' subscales proposed by Mirabile (2014), though it should be noted that his analysis included two additional emotion subscales not assessed in the current study (sadness and happiness), and his participants ranged from three to six years of age, representing a wider age range.

The fear regulation subscale derived from the current analysis of the ERSQ is composed of three strategies: self-directed speech, constructive coping, and information gathering. Selfdirected speech involves talking oneself through a problem (e.g., saying to oneself: "this is just pretend"); constructive coping involves active attempts to remove or deal with the emotioninducing situation (e.g., facing a situation rather than avoiding it); and information gathering involves asking a trustworthy person for information or guidance concerning the emotioneliciting stimulus (e.g., asking a parent about something scary on TV). Of note, this grouping is consistent with previous conceptualizations of active regulatory strategies for dealing with anger 
and sadness, which have been linked to optimal outcomes (Grolnick et al., 1996; Penela et al., 2015; Silk et al., 2006; Zeman et al., 2002). Active emotion regulation strategies, such as problem-solving or soliciting information, have previously been found to predict children's social adjustment (Blair et al., 2004) and may serve a protective role against anxiety and depression (Folk, Zeman, Poon, \& Dallaire, 2014; Suveg \& Zeman, 2004). In a recent study, Wu and colleagues (Wu, Feng, Hooper, \& Ku, 2017) identified a subset of adaptive emotion regulation strategies among preschoolers involving elevating positive emotion and engaging in constructive play, which appears to corroborate the current findings.

Although preliminary in nature, the results from the current study intimate at an organization of emotion regulation strategies unique to fear (i.e., deviating from the traditional active, passive, disruptive categorization). For example, disruptive strategies (e.g., venting, aggression) appeared to be more relevant for anger than fear. This makes sense, as anger and fear are characterized by distinct behavioural and physiological profiles, with anger constituting approach tendencies and fear constituting avoidance tendencies (Carver \& Harmon-Jones, 2009). Children are less likely to express fear in an aggressive manner since fear typically triggers avoidance behaviours.

Anger regulation was assessed in the present study as a comparison to that of fear regulation. One internally reliable subscale of anger regulation was extracted from the ERSQ, representing anger dysregulation, and this index was only negatively associated with fear regulation and not with other study variables, indicating poor validity of this index of anger regulation. It is possible that some strategies included in this measure have limited validity for use with preschool children (e.g., 'Suppression'), and should be either rephrased or eliminated altogether. This is evident in the 'constructive coping' strategy, which is theorized to be 
adaptive. However, as it pertains to anger, the exemplar behaviour reads: "S/he tries to get the object s/he can't have" - a behaviour that may be interpreted by parents as reflecting impulsivity and disinhibition, rather than regulated behaviour. Regardless, the apparent lack of empirical support for the validity of this index makes it difficult to draw firm conclusions about the relative importance anger regulation (as a comparison to fear regulation) in shy children's social adjustment. Although the results suggest that fear regulation may be more relevant to outcomes associated with shyness, it cannot be ruled out that, with a more valid measure of anger regulation, its role would be comparable.

One substantial issue surrounding the current assessment of emotion regulation strategies via the ERSQ concerns the restricted nature of its hypothetical scenarios. The ERSQ prompts respondents to consider how their child behaves when angry or afraid, and it provides an angerand a fear-eliciting scenario, respectively, as examples. Regarding anger, the situation entails the child wanting a toy they cannot have; for fear, it entails watching a scary movie. These examples were unchanged in the current study for consistency. Respondents were not instructed to refer exclusively to these scenarios when answering the questions, but it is possible that the item content may have influenced their responses, to some extent. Accordingly, using a diversity of scenarios, including ones that are more developmentally appropriate (e.g., "seeing a scary clown" for fear; "losing a game" for anger), may serve to bolster the scale's psychometric properties among younger children. This is particularly important as there is evidence to suggest children's use of emotion regulation strategies is heavily context-dependent, with preschoolers relying on more physical strategies (i.e., aggression) when not in the presence of adults (Kurki, Järvenoja, Järvelä, \& Mykkänen, 2017).

\section{Concomitants of Fear Regulation}


Overall, the index of fear regulation in the current study demonstrated reasonable construct validity, correlating significantly with measures across two domains: temperament (shyness) and parenting characteristics (emotion coaching), and approaching significance in predicting a third domain, educator-rated social adjustment (asocial behaviour). These findings are discussed in turn.

Consistent with the hypotheses, the results showed a significant negative correlation between fear regulation and shyness, suggesting that shy children employ these active fear regulation strategies less frequently. This study is among the first to demonstrate the linkages between shyness and fear regulation in preschoolers, and provides some initial evidence of the validity of this index of preschool children's fear regulation. Importantly, the negative association between shyness and fear regulation implies that respondents on this measure were not simply reporting children's fear reactivity, otherwise a positive correlation would be expected.

Preliminary evidence of discriminant validity is suggested by the comparative strength of the link between shyness and fear regulation to that which was nonsignificant for anger regulation (although as mentioned previously - results regarding the anger regulation scale should be considered with caution). This provides initial evidence that fear regulation, specifically, may be more pertinent to shyness. Shy children have previously been found to process emotions differently compared to nonshy children (Fox et al., 1995), and neurophysiological evidence further points to differences among shy children in anterior brain regions involved in regulating fear (Schmidt, Polak, \& Spooner, 2005; Theall-Honey \& Schmidt, 2006). Evidence from the current study advances this line of inquiry further to suggest that shyness is also specifically associated with differences in fear regulation strategy usage. This is 
consistent with previous findings in older children suggesting that shy children employ more internalizing coping strategies (e.g., crying, ruminating) in anxiety-provoking situations (Findlay, Coplan, \& Bowker, 2009; Kingsbury et al., 2013). Early differences in shy children's fear regulation strategy usage may be viewed as a precursor to the ensuing development of coping strategies in middle childhood.

Links between shyness (and related constructs) and emotion regulation strategies have been demonstrated in previous research with children. Feng and colleagues (2011) observed that shy preschoolers employed fewer active regulatory strategies during a disappointment paradigm, which predicted increased internalizing behaviours during middle childhood. In corroboration with Feng and colleagues' findings, Penela and colleagues (2015) found that shy children often resort to more passive emotion regulation strategies when dealing with frustration, such as selfsoothing and distraction, which predicts decreased social competence.

However, in the current study, it was not possible to directly assess links between shyness and passive regulatory strategies for fear. Although passive emotion regulation strategies were included in the ERSQ items, they did not load together on a single cohesive factor. One explanation could be that young children may use passive regulatory strategies infrequently during fearful situations compared to anger-inducing situations. Indeed, regarding anger regulation, the results indicated what could be interpreted as a passive anger regulation factor (Factor \#2), although the internal reliability of this subscale was too suspect to be included in more complex analyses. An alternative explanation is that passive fear regulatory strategies are relatively inconspicuous compared to more overt active regulatory strategies. In short, passive strategies may commonly go unnoticed or unrecognized by parents, resulting in an artificially low prevalence of this particular set of strategies. Notwithstanding, the negative relation between 
shyness and active fear regulation points to potential deficiencies in shy children's implementation of putatively adaptive fear regulation strategies.

Fear regulation was also positively associated with emotion coaching parenting, suggesting that this style of parenting may promote children's implementation of adaptive fear regulation strategies. This is consistent with previous research with older samples demonstrating that emotion coaching parenting predicts greater emotional and behavioural regulation (LagacéSéguin \& Gionet, 2009; Shortt, Stoolmiller, Smith-Shine, Eddy, \& Sheeber, 2010). Parents who are more accepting and supportive of their child's negative emotions help to alleviate fear reactivity and promote optimal strategies for dealing with intense emotions (Katz et al., 2012). It is also possible that children with greater fear regulation evoke more emotion coaching behaviours from their parents, as parents may be better able to respond in a supportive manner toward children who are well-regulated. Regardless, this association provides additional evidence of validity for the index of fear regulation.

Associations between fear regulation and educator-rated outcomes at preschool were limited. Fear regulation only negatively predicted asocial behaviour (at a trend level), suggesting that fear regulation may be marginally associated with less solitary play among preschoolers. Contrary to expectations, fear regulation did not directly predict anxious behaviours or peer exclusion. Among older children, emotion dysregulation is a reliable predictor of internalizing behaviours and difficulties interacting with peers (e.g., Blair et al., 2015; Folk et al., 2014). However, the current results suggest that fear regulation may have less direct impact on preschool children's internalizing behaviours. Nevertheless, the overall pattern of associations with fear regulation across various domains and sources (i.e., parents and teachers) provides promising initial evidence of its validity. 


\section{Shyness and Social Adjustment}

Overall, shyness predicted some aspects of educator-rated child social adjustment. Consistent with previous research (e.g., Coplan et al., 2014), shyness was negatively associated with aggression and positively related to asocial behaviours. Previous research indicates that shy children engage more frequently in solitary activities (Coplan et al., 1994; 2004b; 2008), and the current study demonstrates that shyness predicts these behaviours even in one of the earliest social contexts. Shyness did not, however, significantly predict anxiety, peer exclusion, or prosocial behavior in the preschool. These results are somewhat inconsistent with previous findings using preschool samples. For instance, Graham and Coplan (2012) found that shy preschoolers were rated by educators as exhibiting more anxious behaviours, and Sette and colleagues (2014) found similar associations between shyness and internalizing behaviours among a sample of Italian preschoolers.

The age of the current sample may have contributed to the weaker than expected associations observed among shyness and social adjustment. Whereas much of the previous research has largely employed samples consisting of older preschoolers and kindergartners (ages 4-6), the current study assessed a substantially younger sample of preschoolers (ages 3-4). There are substantive changes in the social environment and peer relationships between the ages of 2-5 years (Coplan \& Arbeau, 2009). For example, among younger preschoolers certain behaviours and peer-related experiences, such as peer exclusion, may be less noticed by educators (e.g., (Fanger, Frankel, \& Hazen, 2012). Even among older preschoolers, exclusionary behaviours are relatively inconspicuous, taking on the form of ignoring others as opposed to outward rejection (Arnold, Homrok, Ortiz, \& Stowe, 1999). 
The current results also provided some (marginally statistically significant) evidence to suggest that child age moderates the relation between shyness and asocial (i.e., socially withdrawn) behaviours. Specifically, shyness was significantly associated with the later display of asocial behaviour among older ( $\geq 4$ years of age), but not among younger $(\leq 3$ years of age) preschoolers. Although this effect only approached statistical significance, it may provide some indication that age plays a role in the outcomes associated with shyness. In keeping with this trend, results also showed a trend-level moderation of age between shyness and peer exclusion. The (marginally significant) negative association among shyness and peer exclusion among three-year-olds became positive in sign among four-year-olds. This suggests that there may be an age-related change in slope for the prediction of peer exclusion from shyness. Educators may not recognize socially withdrawn behaviours in younger preschoolers, given that solitary and parallel play is relatively normative at this early age (Eggum-Wilkens et al., 2014). In older preschoolers, as interactive play proliferates, shy children's withdrawn behaviours may become more evident.

Alternatively, it is possible that, at an early age and in a particularly nurturing and supportive environment, shyness may not necessarily be deleterious to children's peer relations. Among younger preschoolers where the principal source of peer conflict arises from resource distribution and object-conflict (Dunn \& Herrera, 1997), if shy children are more acquiescent toward their more exuberant counterparts (Chen, Fein, \& Tam, 2001) they may be viewed more positively by peers. Similarly, in situations where play resources are limited, shy children may also be less likely to express anger or frustration when other children use their toys (Stewart \& Rubin, 1995), and in group play scenarios shy children are more likely to comply with their peers' decisions rather than confront them (Asendorpf, 1991). Extrapolating this trend further, it is possible that, as children enter kindergarten and elementary school, the association between 
shyness and peer exclusion could become significantly positive, as peers become more selective in their playmates (e.g., Sette, Baumgartner, Laghi, \& Coplan, 2016).

The preschool and childcare environments may also offer certain advantages to young shy children that are less evident as these children enter formal education. For many children, preschool childcare represents one of the earliest forays into the world of peer relations. Thus, these environments provide young children with a great deal of support in their exploration of social interactions with peers (Coplan, Findlay, \& Schneider, 2010). Although shy children may initially experience greater distress in such a novel and stimulating environment (Dettling et al., 1999; O’Laughlin, Meeker, \& Bischoff, 2000), they typically adjust well over time and experience comparative gains in social competence. Additionally, shy children in preschool may also develop high quality relationships with educators, which can serve to attenuate social maladjustment and promote positive interactions with peers (Hipson \& Séguin, 2016).

\section{Complex Pathways Linking Shyness, Fear Regulation, and Adjustment}

Although fear regulation did not directly mediate the association between shyness and subsequent prosocial behaviour, child age was found to be a significant moderator among these associations. Specifically, fear regulation completely mediated the conditional indirect effect (negative association) between shyness and prosocial behaviour (via fear regulation) among older children ( $\geq 4$ years of age), but not among younger children ( $\leq 3$ years of age). This moderation of age was significant in the pathway linking fear regulation to prosocial behaviour, whereby fear regulation predicted greater prosocial behaviour among older children and had no effect among younger children. Previous research has established links between externalizing types of emotion regulation (e.g., anger and frustration) and prosocial behaviour (Liew et al., 2011; Scrimgeour et al., 2016). The current study, however, is the first to provide evidence for 
the link between fear regulation and prosocial behaviour. Moreover, this result suggests that, among older preschoolers, the inability to adaptively regulate fear may be one important mechanism linking shyness with deficiencies in prosocial behaviour.

Results from the current study suggest that shy children use fewer active regulatory strategies when dealing with fear, which in turn negatively predicted later prosocial behaviours particularly among older preschoolers. Concerning these children, one interpretation of this result is that implementing active fear regulation strategies may help to reduce fear reactivity in novel social situations, thereby allowing children to focus on others as opposed to their own distress. Consistent with this supposition, recent evidence suggests that emotionally regulated preschool children are more readily able to orient toward other's needs (Song, Colasante, \& Malti, 2017). This, in turn serves to promote feelings of sympathy and trust, thus increasing prosocial behaviours. Because shy children use fewer active fear regulation strategies, they may experience greater fear reactivity in social situations and, in turn, avoid opportunities to engage prosocially among peers. This dovetails with the notion that fear dysregulation is characteristic of a threat-avoidance bias (Humphreys et al., 2016; Morales et al., 2015; Pérez-Edgar et al., 2011), prompting children to disengage from opportunities for prosocial interactions. Additionally, other researchers have postulated that shy children may respond to others' distress with excessive empathy, resulting in overwhelming emotions that prevents them from engaging in prosocial behaviours (Findlay, Girardi, \& Coplan, 2006). According to this view, shy children are highly empathetic toward others, but their inability to regulate intense feelings of empathy simultaneously inhibits their ability to act sympathetically.

Developmental progressions in children's social interactions and play may also help to explain these age differences. As peer-based group play becomes increasingly frequent with age 
(Coplan \& Arbeau, 2009; Rubin, Bukowski, \& Parker, 2006), shy children's fear dysregulation may also contribute to a lack of engagement in group activities, which could hamper opportunities to act prosocially toward others (Buhs, Rudasill, Kalutskaya, \& Griese, 2015). Shy children often desire to engage in social activities with peers, yet simultaneously experience feelings of fear and anxiety in these situations (Asendorpf, 1990; Coplan et al., 2004b). An inability to control this fear may result in shy children turning down such opportunities, resorting instead to solitary play. Over the course of frequent hesitation to participate in activities with peers, shy children may become less socially competent relative to their more sociable peers. This framework is consistent with that proposed by Penela and colleagues (2015) where shy preschoolers' maladaptive emotion regulation predicted deficits in social skills.

Among younger preschoolers, fear regulation did not contribute to greater prosocial behaviour. It is possible that separate factor analyses within each age group would have revealed different factor solutions, resulting in a set of fear regulation strategies more pertinent to younger preschoolers' adjustment outcomes ${ }^{2}$. Alternatively, parents of three-year-olds may have had fewer opportunities to observe their children fear regulation strategies in contexts that are more relevant to their social adjustment (e.g., childcare), whereas among four-year-olds, parents may be more familiar with their child's fear regulation strategies in childcare and across other social situations.

Another interpretation of this finding is that fear regulation becomes more important for prosocial behaviour with age. In general, there is evidence to suggest that emotion regulation becomes a stronger predictor of optimal social functioning with age (Spinrad et al., 2006). At three years of age, peer relations are rudimentary, as preschoolers are learning how to interact

\footnotetext{
${ }^{2}$ Limited sample size precluded separate factor analyses for each age group. However, the internal consistency of the fear regulation subscale was found to be comparable between age groups: $a=.69$ and .72 for younger and older children, respectively.
} 
positively with others and play cooperatively (Ramani \& Brownell, 2014). Moreover, peer-based play occurs less frequently among three-year-olds and is more often facilitated and guided by educators (Coolahan, Fantuzzo, Mendez, \& McDermott, 2000; Yang, Zou, \& Bergen, 1995). As such, fear regulation may be less influential in these early peer interactions when there are fewer social expectations from peers. In contrast, it is aggressive behaviours that tend to be more damaging to three-year-olds' peer relations, whereas solitary and anxious behaviours appear to be somewhat benign until about four to five years of age (Johnson, Ironsmith, Snow, \& Poteat, 2000). It is at this later age that, with increasing social expectations from peers, shy children's lack of adaptive fear regulation strategies may have a considerable negative impact on their prosocial interactions.

\section{Emotion Coaching and Social Adjustment}

The hypothesis that parental emotion coaching would moderate the pathways linking shyness to fear regulation and subsequent indices of social adjustment was not supported. This was somewhat surprising given the well-established links between children's emotion regulation, parental emotion socialization, and behaviours with peers in early educational contexts (Blair et al., 2004; Carlson \& Wang, 2007; Root \& Rasmussen, 2017; Wu et al., 2017). Apart from its positive correlation with fear regulation, emotion coaching only approached significance in its negative association with shyness, suggesting that shyness elicits marginally less emotion coaching from parents, or that emotion coaching reduces shy behaviours in children.

It was generally anticipated that emotion coaching would have a beneficial or protective effect on children's social adjustment. The current results, however, did not demonstrate such a pattern. Previous research has, indeed, demonstrated links between emotion coaching and positive outcomes among adolescents (Cunningham et al., 2009; Lagacé-Séguin \& Gionet, 
2009), however, results among younger children are more complex. For example, Lagacé-Séguin and Coplan (2005) found that, among preschool children, emotion coaching predicted greater anxious behaviours among highly regulated children compared to those with average behavioural regulation. Similarly, the relation between emotion coaching and prosocial behaviour was positive among dysregulated children, but negative among highly regulated preschoolers.

These previous findings would suggest that the relation between emotion coaching and social adjustment in young children is more consistent with the notion of goodness of fit, where temperament characteristics that are consonant with the demands of the environment are more conducive to optimal outcomes (Hipson \& Séguin, in press; Thomas \& Chess, 1977). Perhaps shy children benefit more from a parenting approach that combines aspects of emotion coaching with aspects of authoritative parenting, whereby parents are accepting of children's fear, but simultaneously do not allow them to avoid certain fear-inducing scenarios (Coplan et al., 2008; Coplan, Hastings, Lagacé-Séguin, \& Moulton, 2002). Alternatively, Castro, Halberstadt, and Garrett-Peters (2017) found that emotionally supportive parenting was associated with greater social maladjustment among third-grade children as rated by teachers, but not as rated by mothers. They proposed a reverse relation, whereby children's social difficulties in school evoked more parental emotional support, as a way for parents to promote more adaptive social behaviours. In other words, emotion coaching may emerge in later childhood as a response to curtail children's social maladjustment; a finding that is potentially mirrored among younger children.

It is also possible that the assessment of emotion coaching used in the present study, which only included items pertaining to children's anger and sadness, may not have adequately captured parents' responses toward children's fear. Although emotion coaching was, indeed, 
positively associated with children's active fear regulation strategies, it is possible that a concerted effort to directly address how parents respond specifically to their child's fear reactions may have revealed stronger associations with outcomes. A previous iteration of the MESQ included items related to worry, which served to increase its overall internal consistency and predictions with indices of social adjustment (e.g., Wilson, Havighurst, \& Harley, 2012). Accordingly, future research with this measure should incorporate these items pertaining to worry/fear.

\section{Implications and Future Directions}

The results from the current study add to our understanding of the links between shyness, fear regulation, socio-emotional development. Previous assessments of young children's fear regulation have largely neglected the specific strategies that children use to regulate fear, which has resulted in some confusion surrounding the distinction between fear reactivity and fear regulation (Thompson, 2011). The methods used in this study have helped to overcome some of these issues by addressing children's regulatory strategies when they are afraid. Notably, this study has shown some evidence of validity of the ERSQ for use with preschool children; particularly the items pertaining to fear.

One of the strengths of the current study was the comparison of fear and anger regulation strategies relative to children's shyness and social adjustment. Traditionally, emotion regulation in children has been assessed in terms of anger or frustration regulation, at the expense of commonly neglected fear regulation. A handful of studies have attempted to address this issue (e.g., Buss, 2011; Mirabile, 2014), however, the current study is the first to directly compare anger and fear regulation strategies among preschoolers. The results confirm the expectation that fear regulation is more relevant in shy children's social adjustment. Moving forward, these 
findings are impetus for future research to assess the regulation of specific emotions, as it may reveal insights into how children of different temperaments regulate specific emotions.

The relation between fear regulation and prosocial behaviour among older preschoolers may have implications for the development of socially anxious behaviours. Buss and colleagues (2013) found that toddlers who exhibited greater fear dysregulation (measured by heightened fear reactivity in non-threatening contexts) and diminished prosocial behaviour were warier during a free play session with an unfamiliar peer. These children also scored higher on parentreported social anxiety symptomology upon entering kindergarten. Over the long-term, the inability to implement adaptive regulatory strategies is one of many risk factors for depression and anxiety among older children and adolescents (Campbell-Sills, Ellard, \& Barlow, 2013). Taken together with the current findings, it is possible that the relation between fear regulation and prosocial behaviour may exacerbate socially withdrawn behaviours among temperamentally shy children.

These findings may also bear on clinical and education practice with young children. For example, efforts to ameliorate children's emotion regulation could consider fear regulation instead of focusing solely on anger regulation, especially for children who display more internalizing behaviours. Although the majority of shy children do not become socially anxious (Biederman et al., 2001), extremely shy preschoolers may benefit from interventions designed to promote the use of active fear regulation strategies in social situations. Indeed, emotion-focused interventions, where children are taught how to recognize and regulate emotions, have been implemented successfully to reduce young children's anxious behaviours (Suveg, Kendall, Comer, \& Robin, 2006). Despite having a temperamentally-based disinclination to engage in active fear regulation, shy children who are encouraged to employ these strategies early on may 
avoid potential issues in social adjustment (Penela et al., 2015). As the current findings suggest, less active fear regulation may not necessarily be indicative of shy children's social maladjustment during the first year of preschool childcare, but there is some reason to believe that it becomes a risk factor as children prepare to enter formal education.

Despite these promising results, the current study is not without limitations. First, the correlational nature of the data does not enable causal interpretations of the associations linking shyness, fear regulation, and prosocial behaviour. For example, it may be that among older preschoolers, engaging in prosocial behaviours promotes fear regulation and reduces shy behaviours. Although the short-term longitudinal design of the study permits some preliminary interpretations for predicting children's social adjustment via shyness and fear regulation, more rigorous long-term designs (e.g., cross-lagged longitudinal designs) are required to further support potential causal pathways among these variables.

Second, the reliance of parent and educator reports raises some issues regarding sharedmethod variance among the observed associations (e.g., shyness and fear regulation). Additionally, parents in the sample reported greater levels of educational attainment and marital status compared to the national average, and thus may not be entirely representative of Canadian children and parents. Future researchers should consider using a broader sample and employing observational designs in conjunction with parent and educator reports to further establish reliability and validity of these assessments. Third, the role of child age should be interpreted with some caution as age was assessed categorically in terms of years, as opposed to months. In turn, the age groups are unequal, with the younger age group containing 187 children $(\sim 75 \%)$ and the older group containing significantly fewer at 61 . 
Data from the current study was also obtained across two geographically distinct sites (Ottawa and Halifax). This approach may be considered to strengthen the generalizability of the findings, though some initial between-site differences were observed that may have confounded some of the findings. By virtue of differences in school board policies between the two regions, the Ottawa sample disproportionately consisted of younger children ( $\leq 3$ years of age), whereas the Halifax sample had a roughly equal age distribution. Consequently, across the entire sample, most of the older children ( $\geq 4$ years of age) were from the Halifax sample. As a result of the confounding of age and site, it cannot be entirely ruled out that site contributed toward the observed age differences. Theoretically, there is no reason to believe that geographical differences contributed to the findings. Parental education and ethnicity did not differ widely between sites, and the disparity cannot be attributed to cultural variations between the two regions. Thus, it makes more theoretical sense to interpret the findings according to age-related progressions in socio-emotional development.

The lack of significant gender differences among the relations between shyness and social adjustment was perhaps surprising given growing evidence to suggest that among older children, shyness appears to have more negative social consequences (e.g., peer rejection/exclusion) for boys than for girls (Doey et al., 2013). It is possible that these differences may only emerge later as children enter formal education and peer interactions become more prevalent. For example, Doey and colleagues (2013) suggested that shy boys experience fewer positive social interactions with parents, peers, and teachers, which serves to exacerbate the negative consequences of shyness. Results from the current study tentatively suggest that the associations between shyness and social difficulties are stronger among older preschoolers. Thus, 
it is possible that gender differences may emerge in concordance with developmental changes in the linkages between shyness and socio-emotional functioning.

Factor analysis of the ERSQ revealed two internally reliable subscales, however, many of the strategies included in this measure were not used in subsequent analyses due to questionable psychometrics. This suggests that a substantial piece may be "missing" from the overall picture of children's anger and fear regulation strategies. The index of anger dysregulation demonstrated noticeably poor validity, and, therefore, may not be an adequate comparison to that of fear regulation. Future iterations of this measure should include more developmentally-appropriate items, as well as a greater variety of emotion-eliciting scenarios to improve ecological validity.

Fear regulation is a relatively nascent construct in developmental research, and measurements of this construct are concordantly preliminary. A parent-report assessment of fear regulation strategies shows some initial promise, but is still limited in terms of its validity. Namely, the conceptual issue persists as to whether children who evince little fear are exerting superior fear regulation, or they simply have low fear reactivity (e.g., Thompson, 2011). With the current measure of fear regulation, there are issues regarding how low fear reactive children would score (e.g., would they erroneously score low on active fear regulation if they rarely express fear?). From an observational (e.g., regulatory strategy-based) standpoint, these dualprocesses are inextricably linked. Nevertheless, physiological measures of children's fear reactivity obtained in concert with their observed fear regulation strategies may distinguish between the two. Moreover, interview-based procedures with older children would permit researchers to directly ask children about the strategies that they use for regulating fear and anger as well as the intensity of their fear responses to various hypothetical situations (e.g., Sala, Pons, \& Molina, 2014). 
Finally, future research should address the role of emotion knowledge among these associations. Emotion knowledge, broadly defined as the ability to recognize emotions and their antecedents/consequences (Denham, 2003), has been identified as a potential moderator in the associations among shyness and social adjustment (Sette et al., 2016). Future researchers should consider whether shy children's relative lack of active fear regulation strategies stems from deficits in competence and/or performance. In other words, are shy children less knowledgeable about adaptive ways of regulating fear, or are they aware of which strategies are adaptive yet fail to properly implement these strategies because of the intensity of their fear? Preliminary research with six- to nine-year-olds suggests that pictorially-based interviews assessing emotion regulation strategy understanding are reliable and valid (Waters \& Thompson, 2014). Future researchers could refine this approach for use with preschool children to examine their understanding of fear regulation strategies.

\section{Conclusions}

Using a newly adapted assessment of fear regulation for preschool children, the current study sought to examine fear regulation as a mediator in the prediction of shyness to social adjustment in preschool childcare, as well as the role of parental emotion socialization. Results demonstrated acceptable evidence of internal reliability and convincing evidence of external validity with this index of fear regulation for use with preschoolers. Overall, the results offered some evidence of the importance of fear regulation in young, shy children's social adjustment; however, evidence of a moderating role of parental emotion coaching was unexpectedly absent. Shyness was negatively associated with fear regulation, though fear regulation only proceeded to predict prosocial behaviour, and only among older preschoolers. Among older preschoolers, shy 
children's lack of adaptive fear regulation strategies may hinder their ability to act prosocially toward peers.

Despite this finding, fear regulation was not a factor in most aspects of social adjustment addressed in the current study. The findings hint at the existence of an age-related mechanism underpinning the social implications of fear regulation, yet more robust measurements of fear regulation assessed across multiple time points are necessary to confirm and expand upon these findings. Nevertheless, the current findings shed light on the potential linkages between fear regulation and early social adjustment among shy preschoolers. For shy children who are struggling to interact positively with peers, it may be more appropriate for parents and (in extreme cases) clinicians to look beyond shy children's anger and frustration, and instead concentrate their efforts specifically on fear regulation. 


\section{References}

Aldao, A., Jazaieri, H., Goldin, P. R., \& Gross, J. J. (2014). Adaptive and maladaptive emotion regulation strategies: Interactive effects during CBT for social anxiety disorder. Journal of Anxiety Disorders, 28, 382-389. doi:10.1016/j.janxdis.2014.03.005

Aldao, A., Nolen-Hoeksema, S., \& Schweizer, S. (2010). Emotion regulation strategies across psychopathology: A meta-analytic review. Clinical Psychology Review, 30, 217-237. doi:10.1016/j.cpr.2009.11.004

Arnold, D. H., Homrok, S., Ortiz, C., \& Stowe, R. M. (1999). Direct observation of peer rejection acts and their temporal relation with aggressive acts. Early Childhood Research Quarterly, 14(2), 183-196.

Asendorpf, J. B. (1990). Beyond social withdrawal: Shyness, unsociability and peer avoidance. Human Development, 33, 250-259.

Asendorpf, J. B. (1991). Development of inhibited children's coping with unfamiliarity. Child Development, 62, 1460-1474.

August, E. G., Stack, D. M., Martin-Storey, A., Serbin, L. A., Ledingham, J., \& Schwartzman, A. E. (2015). Emotion regulation in at-risk preschoolers: Longitudinal associations and influences of maternal histories of risk. Infant and Child Development. doi:10.1002/icd

Aureli, T., Coppola, G., Picconi, L., Grazia, A., \& Ponzetti, S. (2015). Relationship between regulatory temperament dimensions and self-regulatory behaviors at 4 and 6 months of age. Infant Behavior \& Development, 38, 162-166. doi:10.1016/j.infbeh.2014.12.013

Biederman, J., Hirshfeld-Becker, D. R., Rosenbaum, J. F., Hérot, C., Friedman, D., Snidman, N., ... \& Faraone, S. V. (2001). Further evidence of association between behavioral 
inhibition and social anxiety in children. American Journal of Psychiatry, 158(10), 16731679. doi: 10.1176/appi.ajp.158.10.1673

Blair, B. L., Perry, N. B., O’Brien, M., Calkins, S. D., Keane, S. P., \& Shanahan, L. (2014). The indirect effects of maternal emotion socialization on friendship quality in middle childhood. Developmental Psychology, 50(2), 566-576. doi: 10.1037/a0033532

Blair, B. L., Perry, N. B., O’Brien, M., Calkins, S. D., Keane, S. P., \& Shanahan, L. (2015). Identifying developmental cascades among differentiated dimensions of social competence and emotion regulation. Developmental Psychology, 51(8), 1062-1073. doi: $10.1037 / \mathrm{a} 0039472$

Blair, K. A., Denham, S. A., Kochanoff, A., \& Whipple, B. (2004). Playing it cool: Temperament, emotion regulation, and social behavior in preschoolers. Journal of School Psychology, 42, 419-443.

Braungart-Rieker, J. M., Hill-Soderlund, A. L., \& Karrass, J. (2010). Fear and anger reactivity trajectories from 4 to 16 months: The roles of temperament, regulation, and maternal sensitivity. Developmental Psychology, 46(4), 791-804. doi: 10.1037/a0019673

Braungart-Rieker, J. M., \& Stifter, C. A. (1996). Infants' responses to frustrating situations: Continuity and change in reactivity and regulation. Child Development, 67(4), 17671779. doi: 10.1111/j.1467-8624.1996.tb01826.x

Brooker, R. J., Buss, K. A., Lemery-Chalfant, K., Aksan, N., Davidson, R. J., \& Goldsmith, H. H. (2013). The development of stranger fear in infancy and toddlerhood: Normative development, individual differences, antecedents, and outcomes. Developmental Science, 16(6), 864-878. doi: 10.1111/desc.12058 
Buhs, E. S., Rudasill, K. M., Kalutskaya, I. N., \& Griese, E. R. (2015). Shyness and engagement: Contributions of peer rejection and teacher sensitivity. Early Childhood Research Quarterly, 30, 12-19.

Buss, K. A. (2011). Which fearful toddlers should we worry about? Context, fear regulation, and anxiety risk. Developmental Psychology, 47(3), 804-819. doi: 10.1037/a0023227

Buss, K. A., Davis, E. L., Kiel, E. J., Brooker, R. J., Beekman, C., \& Early, M. C. (2013).

Dysregulated fear predicts social wariness and social anxiety symptoms during kindergarten. Journal of Clinical Child \& Adolescent Psychology, 42(5), 603-616. doi: $10.1080 / 15374416.2013 .769170$

Buss, K. A., Davis, E. L., Ram, N., \& Coccia, M. (2017). Dysregulated fear, social inhibition, and respiratory sinus arrhythmia: A replication and extension. Child Development. Advance online publication. doi: 10.1111/cdev.12774

Calkins, S. D., Dedmon, S. E., Gill, K. L., Lomax, L. E., \& Johnson, L. M. (2002). Frustration in infancy: Implications for emotion regulation, physiological processes, and temperament. Infancy, 3(2), 175-197.

Calkins, S. D., Gill, K. L., Johnson, M. C., \& Smith, C. L. (1999). Emotional reactivity and emotional regulation strategies as predictors of social behavior with peers during toddlerhood. Social Development, 8(3), 310-334. doi: 10.1111/1467-9507.00098

Campbell, S. B. (2006). Behavior problems in preschool children: A review of recent research. Journal of Child Psychology and Psychiatry, 36(1), 113-149. doi: 10.1111/j.14697610.1995.tb01657.x 
Campbell-Sills, L., Ellard, K. K., \& Barlow, D. H. (2013). Emotion regulation in anxiety disorders. In J. J. Gross (Ed.), Handbook of emotion regulation, $2^{\text {nd }}$ edition, (pp. 393412). New York: Guilford.

Campos, J. J., Mumme, D. L., Kermoian, R., \& Campos, R. G. (1994). A functionalist perspective on the nature of emotion. Monographs of the Society for Research in Child Development, 59, 284-303.

Carlson, S. M., \& Wang, T. S. (2007). Inhibitory control and emotion regulation in preschool children. Cognitive Development, 22(4), 489-510.

Carver, C. S., \& Harmon-Jones, E. (2009). Anger is an approach-related affect: Evidence and implications. Psychological Bulletin, 135(2), 183-204.

Castro, V. L., Halberstadt, A. G., Garrett-Peters, P. T. (2017). Changing tides: Mothers' supportive emotion socialization relates negatively to third-grade children's social adjustment in school. Social Development. Advance online publication. doi:10.1111/sode. 12251

Chang, H., Shelleby, E. C., Cheong, J., \& Shaw, D. S. (2012). Cumulative risk, negative emotionality, and emotion regulation as predictors of social competence in transition to school: A mediated moderation model. Social Development, 21(4), 780-800. doi: 10.1111/j.1467-9507.2011.00648.x

Chen, D. W., Fein, G., \& Tam, H. P. (2001). Peer conflicts of preschool children: Issues, resolution, incidence, and age-related patterns. Early Education and Development, 12, 523-544.

Chronis-Tuscano, A., Degnan, K. A., Pine, D. S., Perez-Edgar, K., Henderson, H. A., Diaz, Y., ... \& Fox, N. A. (2009). Stable early maternal report of behavioral inhibition predicts 
lifetime social anxiety disorder in adolescence. American Academy of Child and Adolescent Psychiatry, 48(9), 928-935. doi: 10.1097/CHI.0b013e3181ae09df

Clauss, J. A., \& Blackford, J. U. (2012). Behavioral inhibition and the risk for developing social anxiety disorder: A meta-analytic study. Journal of the American Academy of Child and Adolescent Psychiatry, 51, 1066-1075.

Colder, C. R., Mott, J. A., \& Berman, A. S. (2002). The interactive effects of infant activity level and fear on growth trajectories of early childhood behavior problems. Development and Psychopathology, 14, 1-23. doi:10.1017/S0954579402001013.

Cole, P. M., Dennis, T. A., Smith-Simon, K. E., \& Cohen, L. H. (2009). Preschoolers' emotion regulation strategy understanding: Relations with emotion socialization and child selfregulation. Social Development, 18(2), 324-352. doi: 10.1111/j.1467-9507.2008.00503.x

Cole, P. M., Martin, S. E., \& Dennis, T. A. (2004). Emotion regulation as a scientific construct: Methodological challenges and directions for child development research. Child Development, 75(2), 317-333.

Coolahan, K., Fantuzzo, J., Mendez, J., \& McDermott, P. (2000). Preschool peer interactions and readiness to learn: Relationships between classroom peer play and learning behaviors and conduct. Journal of Educational Psychology, 92(3), 458-465.

Coplan, R. J., \& Arbeau, K. A. (2009). Peer interactions and play in early childhood. In K. H. Rubin, W. Bukowski, \& B. Laursen (Eds.), Handbook of peer interactions, relationships, and groups (pp. 143-161). New York: Guilford.

Coplan, R. J., Arbeau, K. A., \& Armer, M. (2008). Don’t fret, be supportive! Maternal characteristics linking child shyness to psychosocial and school adjustment in kindergarten. Journal of Abnormal Child Psychology, 36, 359-371. 
Coplan, R. J., Findlay, L. C., \& Nelson, L. J. (2004). Characteristics of preschoolers with lower perceived competence. Journal of Abnormal Child Psychology, 32, 399-408.

Coplan, R. J., Findlay, L. C., \& Schneider, B. H. (2010). Where do anxious children "fit" best? Childcare and the emergence of anxiety in early childhood. Canadian Journal of Behavioural Science, 42(3), 185-193.

Coplan, R. J., Hastings, P. D., Lagacé-Séguin, D. G., \& Moulton, C. E. (2002). Authoritative and authoritarian mothers' parenting goals, attributions, and emotions across different childrearing contexts. Parenting, 2(1), 1-26.

Coplan, R. J., Ooi, L. L., \& Nocita, G. (2015). When one is company and two is a crowd: Why some children prefer solitude. Child Development Perspectives, 9(3), 133-137. doi: 10.1111/cdep. 12131

Coplan, R. J., Ooi, L. L., Rose-Krasnor, L., \& Nocita, G. (2014). 'I want to play alone’: Assessment and correlates of self-reported preference for solitary play in young children. Infant and Child Development, 23, 229-238. doi:10.1002/icd.1854

Coplan, R. J., Prakash, K., O’Neil, K., \& Armer, M. (2004). Do you “want” to play? Distinguishing between conflicted shyness and social disinterest in early childhood. Developmental Psychology, 40(2), 244-258.

Coplan, R. J., Reichel, M., \& Rowan, K. (2009). Exploring the associations between maternal personality, child temperament, and parenting: A focus on emotions. Personality and Individual Differences, 46, 241-246. doi:10.1016/j.paid.2008.10.011

Coplan, R. J., Rose-Krasnor, L., Weeks, M., Kingsbury, A., Kingsbury, M., \& Bullock, A. (2013). Alone is a crowd: Social motivations, social withdrawal, and socioemotional 
functioning in later childhood. Developmental Psychology, 49(5), 861-875. doi: $10.1037 / \mathrm{a} 0028861$

Coplan, R. J., Rubin, K. H., Fox, N. A., Calkins, S. D., \& Stewart, S. L. (1994). Being alone, playing alone, and acting alone: Distinguishing among reticence, and passive- and activesolitude in young children. Child Development, 65, 129-138.

Coplan, R. J., \& Weeks, M. (2009). Shy and soft-spoken: Shyness, pragmatic language, and socio-emotional adjustment in early childhood. Infant and Child Development, 18, 238254. doi:10.1002/icd.622.

Coplan, R. J., Wilson, J., Frohlick, S. L., \& Zelenski, J. (2006). A person-oriented analysis of behavioral inhibition and behavioral activation in children. Personality and Individual Differences, 41, 917-927. doi:10.1016/j.paid.2006.02.019

Crozier, W. R. (1995). Shyness and self-esteem in middle childhood. British Journal of Educational Psychology, 65, 85-95.

Cunningham, J. N., Kliewer, W., \& Garner, P. W. (2009). Emotion socialization, child emotion understanding and regulation, and adjustment in urban African American families: Differential associations across child gender. Development and Psychopathology, 21, 261-283. doi:10.1017/S0954579409000157

Davis, E. L., \& Buss, K. A. (2012). Moderators of the relation between shyness and behavior with peers: Cortisol dysregulation and maternal emotion socialization. Social Development, 21(4), 801-820. doi: 10.1111/j.1467-9507.2011.00654.x

Denham, S. A. (2003). Social and emotional prevention and intervention programming for preschoolers. New York: Kluwer Academic/Plenum. 
Dennis, T. (2006). Emotional self-regulation in preschoolers: The interplay of child approach reactivity, parenting, and control capacities. Developmental Psychology, 42(1), 84-97.

Dennis, T. A., \& Hajcak, G. (2009). The late positive potential: A neurophysiological marker for emotion regulation in children. Journal of Child Psychology and Psychiatry, 50(11), 1373-1383. doi:10.1111/j.1469-7610.2009.02168.x

Dettling, A. C., Gunnar, M. R., \& Donzella, B. (1999). Cortisol levels of young children in fullday childcare centres: Relations with age and temperament. Psychoneuroendocrinology, $24(5), 519-536$.

Di Maggio, R., Zuppulla, C., \& Pace, U. (2016). The relationship between emotion knowledge, emotion regulation and adjustment in preschoolers: A mediation model. Journal of Child and Family Studies, 25(8), 2626-2635. doi:10.1007/s10826-016-0409-6

Diener, M. L., \& Kim, D. (2004). Maternal and child predictors of preschool children's social competence. Journal of Applied Developmental Psychology, 25, 3-24. doi:10.1016/j.appdev.2003.11.006

Doey, L., Coplan, R. J., \& Kingsbury, M. (2014). Bashful boys and coy girls: A review of gender differences in childhood shyness. Sex Roles, 70, 255-266. doi:10.1007/s11199-013-03179

Dunn, J., \& Herrera, C. (1997). Conflict resolution with friends, siblings, and mothers: A developmental perspective. Aggressive Behavior, 23, 343-357.

Dyson, M. W., Klein, D. N., Olino, T. M., Dougherty, L. R., \& Durbin, C. E. (2011). Social and non-social behavioral inhibition in preschool-age children: Differential associations with parent-reports of temperament and anxiety. Child Psychiatry and Human Development, 42, 390-405. doi:10.1007/s10578-011-0225-6 
Eggum-Wilkens, N. D., Fabes, R. A., Castle, S., Zhang, L., Hanish, L. D., \& Martin, C. L. (2014). Playing with others: Head Start children's peer play and relations with kindergarten school competence. Early Childhood Research Quarterly, 29(3), 345-356.

Eggum-Wilkens, N. D., Lemery-Chalfant, K., Aksan, N., \& Goldsmith, H. H. (2015). Selfconscious shyness: Growth during toddlerhood, strong role of genetics, and no prediction from fearful shyness. Infancy, 20(2), 160-188. doi:10.1111/infa.12070

Eisenberg, N., Cumberland, A., \& Spinrad, T. L. (1998). Parental socialization of emotion. Psychological Inquiry, 9, 241-273.

Eisenberg, N., Cumberland, A., Spinrad, T. L., Fabes, R. A., \& Shepard, S. A. (2001). The relations of regulation and emotionality to children's externalizing and internalizing problem behavior. Child Development, 72(4), 1112-1134. doi: 10.1111/1467-8624.00337

Eisenberg, N., Fabes, R. A., Guthrie, I. K., \& Reiser, M. (2002). The role of emotionality and regulation in children's social competence and adjustment. In Pulkkinen L, Caspi A (Eds.), Paths to successful development: Personality in the life course (pp. 46-70). Cambridge University Press: New York.

Eisenberg, N., Fabes, R. A., Murphy, B., Maszk, P., Smith, M., \& Karbon, M. (1995). The role of emotionality and regulation in children's social functioning: A longitudinal study. Child Development, 66(5), 1360-1384. doi: 10.1111/j.1467-8624.1995.tb00940.x

Eisenberg, N., Fabes, R. A., \& Spinrad, T. (2006). Prosocial development. In N. Eisenberg (Ed.), Handbook of child psychology: Social emotional, and personality development (6th ed.,Vol. 3, pp. 646-718). Hoboken, NJ: John Wiley \& Sons.

Eisenberg, N., Spinrad, T. L., \& Valiente, C. (2016). Emotion-related self-regulation and children's social, psychological, and academic functioning. In L. Balter \& C. S. Tamis- 
LeMonda (Eds.), Child Psychology: A Handbook of Contemporary Issues (3 ${ }^{\text {rd }}$ ed., pp. 219). Psychology Press.

Eisenberg, N., Valiente C., Morris, A. S., Fabes, R. A., Cumberland, A., Reiser, M., ... \& Losoya, S. (2003). Longitudinal relations among parental emotional expressivity, children's regulation, and quality of socioemotional functioning. Developmental Psychology, 39(1), 3-19. doi: 10.1037/0012-1649.39.1.3

Eisenberg, N., Valiente, C., Spinrad, T. L., Cumberland, A., Liew, J., Reiser, M., ... Losoya, S. H. (2009). Longitudinal relations of children's effortful control, impulsivity, and negative emotionality to their externalizing, internalizing, and co-occurring behavior problems. Developmental Psychology, 45(4), 988-1008. doi:10.1037/a0016213

Evans, D. W., Gray, F. L., \& Leckman, J. F. (1999). The rituals, fears and phobias of young children: Insights from development, psychopathology and neurobiology. Child Psychiatry and Human Development, 29(4), 261-276.

Fanger, S. M., Frankel, L. A., \& Hazen, N. (2012). Peer exclusion in preschool: Naturalistic observations in a playground setting. Merrill-Palmer Quarterly, 58(2), 224-254.

Feng, X., Shaw, D. S., Kovacs, M., Lane, T., O’Rourke, F. E., \& Alarcon, J. H. (2008). Emotion regulation in preschoolers: The roles of behavioral inhibition, maternal affective behavior, and maternal depression. Journal of Child Psychology and Psychiatry, 49(2), 132-141. doi:10.1111/j.1469-7610.2007.01828.x

Feng, X., Shaw, D. S., \& Moilanen, K. L. (2011). Parental negative control moderates the shyness-emotion regulation pathway to school-age internalizing problems. Journal of Abnormal Child Psychology, 39, 425-436. doi: 10.1007/s10802-010-9469-z 
Field, T. (2008). Problems in infancy. In M. Hersen \& A.M. Gross (Eds.), Handbook of clinical Psychology, Vol. 2: Children and adolescents (pp. 966-1011). Hoboken, NJ: John Wiley \& Sons.

Findlay, L. C., Coplan, R. J., \& Bowker, A. (2009). Keeping it all inside: Shyness, internalizing coping strategies and socio-emotional adjustment in middle childhood. International Journal of Behavioral Development, 33, 47-54.

Findlay, L. C., Girardi, A., \& Coplan, R. J. (2006). Links between empathy, social behavior, and social understanding in early childhood. Early Childhood Research Quarterly, 21(3), 347-359.

Folk, J. B., Zeman, J. L., Poon, J. A., \& Dallaire, D. H. (2014). A longitudinal examination of emotion regulation: Pathways to anxiety and depressive symptoms in urban minority youth. Child and Adolescent Mental Health, 19(4), 243-250. doi: 10.1111/camh.1205

Fox, N. A., Henderson, H.A., Marshall, P. J., Nichols, K. E., \& Ghera, M. M. (2005). Behavioral inhibition: linking biology and behavior within a developmental framework. Annual Review of Psychology, 56(1), 235-262. doi:10.1146/annurev.psych.55.090902.141532.

Fox, N. A., Rubin, K. H., Calkins, S. D., Marshall, T. R., Coplan, R. J., Porges, S. W., ... \& Stewart, S. (1995). Frontal activation asymmetry and social competence at four years of age. Child Development, 66, 1770-1784.

Gazelle, H., \& Ladd, G. W. (2003). Anxious solitude and peer exclusion: A diathesis-stress model of internalizing trajectories in childhood. Child Development, 74, 257-278. doi:10.1111/1467-8624.00534. 
Gottman, J. M., Katz, L. F., \& Hooven, C. (1996). Parental meta-emotion philosophy and the emotional life of families: Theoretical models and preliminary data. Journal of Family Psychology, 10, 243-268.

Grady, J. S., Karraker, K., \& Metzger, A. (2012). Shyness trajectories in slow-to-warm-up infants: Relations with child sex and maternal parenting. Journal of Applied Developmental Psychology, 33(2), 91-101.

Graham, A. A., \& Coplan, R. J. (2012). Shyness, sibling relationships, and young children's socioemotional adjustment at preschool. Journal of Research in Childhood Education, 26(4), 435-449. doi:10.1080/02568543.2012.711802

Gramszlo, C., \& Woodruff-Borden, J. (2015). Emotional reactivity and executive control: A pathway of risk for the development of childhood worry. Journal of Anxiety Disorders, $35,35-41$.

Graziano, P. A., Calkins, S. D., \& Keane, S. P. (2011). Sustained attention development during the toddlerhood to preschool period: Associations with toddlers' emotion regulation strategies and maternal behaviour. Infant and Child Development, 20(6), 389-408. doi:10.1002/icd.731

Grolnick, W. S., Bridges, L. J., \& Connell, J. P. (1996). Emotion regulation in two-year-olds: Strategies and emotional expression in four contexts. Child Development, 67(3), 928-941. doi:10.1111/j.1467-8624.1996.tb01774.x

Gross, J. J. (1998). The emerging field of emotion regulation: An integrative review. Review of General Psychology, 2(3), 271-299. 
Gross, J. J. (2013). Emotion regulation: Conceptual and empirical foundations. In J. J. Gross (Ed.), Handbook of emotion regulation, $2^{\text {nd }}$ edition (3-22). New York: The Guilford Press.

Gross, J. J., \& John, O. P. (2003). Individual differences in two emotion regulation processes: Implications for affect, relationships, and well-being. Journal of Personality and Social Psychology, 85, 348-362.

Halberstadt, A. G. (1991). Socialization of expressiveness: Family influences in particular and a model in general. In R. S. Feldman \& S. Rime (Eds.), Fundamentals of emotional expressiveness (pp. 106-162). Cambridge, England: Cambridge University Press.

Halligan, S. L., Cooper, P. J., Fearon, P., Wheeler, S. L., Crosby, M., \& Murray, L. (2013). The longitudinal development of emotion regulation capacities in children at risk for externalizing disorders. Development and Psychopathology, 25, 391-406. doi:10.1017/S0954579412001137

Hane, A. A., Fox, N. A., Henderson, H. A., \& Marshall, P. J. (2008). Behavioral reactivity and approach-withdrawal bias in infancy. Developmental Psychology, 44(5), 1491-1496. doi: $10.1037 / \mathrm{a} 0012855$

Hart, C. H., Yang, C., Nelson, L. J., Robinson, C. C., Olsen, J. A., Nelson, D. A., ... \& Wu (2000). Peer acceptance in early childhood and subtypes of socially withdrawn behavior in China, Russia, and the United States. International Journal of Behavioural Development, 24, 73-81.

Hayes, A. F. (2016). Partial, conditional, and moderated moderated mediation: Quantification, inference, and interpretation. 
Herndon, K. J., Bailey, C. S., Shewark, E. A., Denham, S. A., \& Bassett, H. H. (2013). Preschoolers' emotion expression and regulation: Relations with school adjustment. The Journal of Genetic Psychology, 174(6), 642-663. doi: 10.1080/00221325.2012.759525

Hipson, W. E., \& Séguin, D. G. (2016). Is good fit related to good behaviour? Goodness of fit between daycare teacher-child relationships, temperament, and prosocial behaviour. Early Child Development and Care, 186(5), 785-798. doi:10.1080/03004430.2015.1061518

Hipson, W. E., \& Seguin, D. G. (Advance online publication). Goodness of Fit Model, In: V. Ziegler-Hill, \& T. K. Shackelford (Eds.). Encyclopedia of Personality and Individual Differences. New York: Springer. doi:10.1007/978-3-319-28099-8_757-1

Hourigan, S. E., Goodman, K. L., \& Southam-Gerow, M. A. (2011). Discrepancies in parents' and children's reports of child emotion regulation. Journal of Experimental Child Psychology, 110, 198-212. doi:10.1016/j.jecp.2011.03.002

Humphreys, K. L., Kircanski, K., Colich, N. L., \& Gotlib, I. H. (2016). Attentional avoidance of fearful facial expressions following early life stress is associated with impaired social functioning. Journal of Child Psychology and Psychiatry. doi:10.1111/jcpp.12607

Hurrell, K. E., Hudson, J. L., \& Schniering, C. A. (2015). Parental reactions to children's negative emotions: Relationships with emotion regulation in children with an anxiety disorder. Journal of Anxiety Disorders, 29, 72-82. doi:10.1016/j.janxdis.2014.10.008

Izard, C. E. (1991). The psychology of emotions. New York: Plenum.

Johnson, C., Ironsmith, M., Snow, C. W., \& Poteat, G. M. (2000). Peer acceptance and social adjustment in preschool and kindergarten. Early Childhood Education Journal, 27(4), 207-212. 
Kagan, J., Reznick, J. S., Clarke, C., Snidman, N., \& Garcia-Coll, C. (1984). Behavioral inhibition to the unfamiliar. Child Development, 55(6), 2212-2225.

Kagan, J., Snidman, N., \& Arcus, D. (1998). Childhood derivatives of high and low reactivity in infancy. Child Development, 69(6), 1483-1493.

Karevold, E., Ystrøm, E., Coplan, R. J., Sanson, A., \& Mathiesen, K. S. (2012). A prospective longitudinal study of shyness from infancy to adolescence: Stability, age-related changes, and prediction of socio-emotional functioning. Journal of Abnormal Child Psychology, 40, 1167-1177.

Katz, L. F., Maliken, A. C., \& Stettler, N. M. (2012). Parental meta-emotion philosophy: A review of research and theoretical framework. Child Development Perspectives, 6(4), 417-422. doi: 10.1111/j.1750-8606.2012.00244.x

Kingsbury, M., Coplan, R. J., \& Rose-Krasnor, L. (2013). Shy but getting by? An examination of the complex links among shyness, coping, and socioemotional functioning in childhood. Social Development, 22(1), 126-145. doi: 10.1111/sode.12003

Kurki, K., Järvenoja, H., Järvelä, S., \& Mykkänen, A. (2017). Young children's use of emotion and behaviour regulation strategies in socio-emotionally challenging day-care situations. Early Childhood Research Quarterly, 41, 50-62.

Ladd, G. W., Herald-Brown, S. L., \& Andrews, R. K. (2009). The child behavior scale (CBS) revisited: A longitudinal evaluation of CBS subscales with children, preadolescents, and adolescents. Psychological Assessment, 21(3), 325-339. doi:10.1037/a0016205

Ladd, G. W., Kochenderfer-Ladd, B., Eggum, N. D., Kochel, K. P., \& McConnell, E. M. (2011). Characterizing and comparing the friendships of anxious-solitary and unsociable 
preadolescents. Child Development, 82, 1434-1453. doi:10.1111/j.14678624.2011.01632.x.

Ladd, G. W., \& Profilet, S. M. (1996). The child behavior scale: A teacher-report measure of young children's aggressive, withdrawn, and prosocial behaviors. Developmental Psychology, 32(6), 1008-1024.

Lagacé-Séguin, D. G., \& Coplan, R. J. (2005). Maternal emotional styles and child adjustment: Assessment, correlates, outcomes and goodness of fit in early childhood. Social Development, 14(4), 613-636.

Lagacé-Séguin, D. G., \& Gionet, A. (2009). Parental meta-emotion and temperament predict coping skills in early adolescence. International Journal of Adolescence and Youth, 14, 367-382.

Lewis, M. (2000). The emergence of human emotions. In M. Lewis \& J. M. Haviland-Jones (Eds.), Handbook of emotions 2nd ed., (pp. 265-280). New York: Guilford Press.

Liew, J., Eisenberg, N., Spinrad, T. L., Eggum, N. D., Haugen, R. G., Kupfer, A., ... Baham, M. E. (2011). Physiological regulation and fearfulness as predictors of young children's empathy-related reactions. Social Development, 20, 111-134.

Lonigan, C. J., Vasey, M. W., Phillips, B. M., \& Hazen, R. A. (2004). Temperament, anxiety, and the processing of threat-relevant stimuli. Journal of Clinical Child and Adolescent Psychology, 33(1), 8-20.

Mennin, D. S., \& Fresco, D. M. (2014). Emotion regulation therapy. In J. J. Gross (Ed.), Handbook of Emotion Regulation $2^{\text {nd }}$ ed., (pp. 469-490). New York: Guilford Press.

Miller, R. L., Dunsmore, J. C., \& Smith, C. L. (2015). Effortful control and parents' emotion socialization patterns predict children's positive social behavior: A person-centered 
approach. Early Education and Development, 26(2), 167-188.

doi:10.1080/10409289.2015.975034.

Mirabile, S. P. (2014). Parents' inconsistent emotion socialization and children's socioemotional adjustment. Journal of Applied Developmental Psychology, 35, 392-400. doi:10.1016/j.appdev.2014.06.003

Mirabile, S. P. (2015). Ignoring children's emotions: A novel ignoring subscale for the coping with children's negative emotions scale. European Journal of Developmental Psychology, 12(4), 459-471. doi:10.1080/17405629.2015.1037735

Morales, S., Beekman, C., Blandon, A. Y., Stifter, C. A., \& Buss, K. A. (2015). Longitudinal associations between temperament and socioemotional outcomes in young children: The moderating role of RSA and gender. Developmental Psychobiology, 57(1), 105-119. doi: $10.1002 / \operatorname{dev} .21267$

Morales, S., Pérez-Edgar, K. E., \& Buss, K. A. (2015). Attention biases toward and away from threat mark the relation between early dysregulated fear and the later emergence of social withdrawal. Journal of Abnormal Child Psychology, 43, 1067-1078. doi:10.1007/s10802014-9963-9

Moran, J. K., Izard, C. E., \& Hyde, C. (2014). Emotional reactivity and regulation in head start children. Links to ecologically valid behaviors and internalizing problems. Social Development, 23(2), 250-266. doi:10.1111/sode.12049

Moran, L. R., Lengua, L. J., \& Zalewski, M. (2013). The interaction between negative emotionality and effortful control in early social-emotional development. Social Development, 22(2), 340-362. doi:10.1111/sode.12025 
Morelen, D., Southam-Gerow, M., \& Zeman, J. (2016). Child emotion regulation and peer victimization: The moderating role of child sex. Journal of Child and Family Studies, 25, 1941-1953. doi:10.1007/s10826-016-0360-6

Morris, A. S., Silk, J. S., Steinberg, L., Myers, S. S., \& Robinson, L. R. (2007). The role of the family context in the development of emotion regulation. Social Development, 16(2), 361-388. doi:10.1111/j.1467-9507.2007.00389.x

Nelson, L. J., Padilla-Walker, L. M., Badger, S., McNamara Barry, C., Carroll, J. S., \& Madsen, S. D. (2008). Associations between shyness and internalizing behaviors, externalizing behaviors, and relationships during emerging adulthood. Journal of Youth and Adolescence, 37(5), 605-615.

Nelson, L. J., Rubin, K. H., \& Fox, N. A. (2005). Social and nonsocial behaviors and peer acceptance: a longitudinal model of the development of self-perceptions in children ages 4 to 7 years. Early Education and Development, 20, 185-200.

O’Laughlin, E. M., Meeker, E. C., \& Bischoff, L. G. (2000). Predictors of children's emotional distress in a mother-absent situation: Implications for caregiving research. Journal of Genetic Psychology, 161(2), 235-252.

Ohman, A. (2000). Fear and anxiety: Evolutionary, cognitive, and clinical perspectives. In M. Lewis \& J. M. Haviland-Jones (Eds.), Handbook of emotions (2nd ed., pp. 573-593). New York, NY:Guilford

Paulussen-Hoogeboom, M. C., Stams, G. J. J. M., Hermanns, J. M. A., \& Peetsma, T. T. D. (2007). Child negative emotionality and parenting from infancy to preschool: A metaanalytic review. Developmental Psychology, 43(2), 438-453. doi: 10.1037/00121649.43 .2 .438 
Penela, E. C., Walker, O. L., Degnan, K. A., Fox, N. A., \& Henderson, H. A. (2015). Early behavioral inhibition and emotion regulation: Pathways toward social competence in middle childhood. Child Development, 86(4), 1227-1240. doi: 10.1111/cdev.12384

Pérez-Edgar, K., Reeb-Sutherland, B. C., McDermott, J. M., White, L. K., Henderson, H. A., Degnan, K. A., ... \& Fox, N. A. (2011). Attention biases to threat link behavioural inhibition to social withdrawal over time in very young children. Journal of Abnormal Child Psychology, 39(6), 885-895. doi:10.1007/s10802-011-9495-5

Prior, M., Smart, D., Sanson, A., \& Oberklaid, F. (2000). Does shy inhibited temperament in childhood lead to anxiety problems in adolescence? Journal of the American Academy of Child and Adolescent Psychiatry, 39, 461-468.

Ramani, G. B., \& Brownell, C. A. (2014). Preschoolers' cooperative problem solving: Integrating play and problem solving. Journal of Early Childhood Research, 12(1), 92108. doi: $10.1177 / 1476718 \times 13498337$

Rapee, R. M., \& Coplan, R. J. (2010). Conceptual relations between anxiety disorder and fearful temperament. In H. Gazelle \& K. H. Rubin (Eds.), Social anxiety in childhood: Bridging developmental and clinical perspectives. New Directions for Child and Adolescent Development, 127, 17-31. San Francisco: Jossey-Bass.

Root, A. E., \& Rasmussen, K. E. (2017). Maternal emotion socialization: The contribution of inhibited behaviour and mothers' dissatisfaction with the parent-child relationship. Infant and Child Development, 26(1), 1-12.

Rosen, J. B., \& Schulkin, J. (1998). From normal fear to pathological anxiety. Psychological Review, 105(2), 321-350. 
Rothbart, M. (1989). Temperament and development. In G. Kohnstamm, J. Bates, \& M. Rothbart (Eds.), Temperament in childhood. New York: Wiley.

Rothbart, M. K., Ahadi, S. A., \& Hershey, K. L. (1994). Temperament and social behavior in childhood. Merrill-Palmer Quarterly, 40(1), 21-39.

Rothbart, M. K. \& Bates, J. E. (2006). Temperament. In W. Damon \& R. Lerner (Series Eds.), \& N. Eisenberg (Vol. Ed.), Handbook of child psychology, Vol. 3. Social, emotional, and personality development (6th ed., pp. 99-166). New York: Wiley.

Rubin, K. H., Bukowski, W. M., \& Parker, J. G. (2006). Peer interaction and social competence. In W. Damon \& R. M. Lerner (Eds.), Handbook of child psychology (6 ${ }^{\text {th }}$ ed., Vol 3.). New York: Wiley.

Rubin, K. H., \& Coplan, R. J. (2004). Paying attention to and not neglecting social withdrawal and social isolation. Merrill-Palmer Quarterly, 50, 506-534. doi:10.1353/mpq.2004.0036.

Rubin, K. H., \& Coplan, R. J. (2010). The Development of Shyness and Social Withdrawal. New York: Guilford.

Rubin, K. H., Coplan, R. J., \& Bowker, J. (2009). Social withdrawal in childhood. Annual Review of Psychology, 60, 141-171.

Rubin, K. H., Coplan, R. J., Fox, N. A., \& Calkins, S. D. (1995). Emotionality, emotion regulation and preschooler's social adaptation. Development and Psychopathology, 7, 4962.

Sala, M. N., Pons, F., \& Molina, P. (2014). Emotion regulation strategies in preschool children. British Journal of Developmental Psychology, 32(4), 440-453. doi:10.1111/bjdp.12055 
Schmidt, L. A., Polak, C. P., \& Spooner, A. L. (2005). Biological and environmental contributions to childhood shyness: A diathesis-stress model. In W. R. Crozier \& L. E. Alden (Eds.), The essential handbook of social anxiety for clinicians (pp. 33-55). West Sussex, UK: John Wiley \& Sons.

Schwartz, C. E., Snidman, N., \& Kagan, J. (1999). Adolescent social anxiety as an outcome of inhibited temperament in childhood. Journal of the American Academy of Child and Adolescent Psychiatry, 38, 1008-1015.

Scrimgeour, M. B., Davis, E. L., \& Buss, K. A. (2016). You get what you get and you don't throw a fit!: Emotion socialization and child physiology jointly predict early prosocial development. Developmental Psychology, 52(1), 102-116. doi:10.1037/dev0000071

Sette, S., Baumgartner, E., Laghi, F., \& Coplan, R. J. (2016). The role of emotion knowledge in the links between shyness and children's socio-emotional functioning at preschool. British Journal of Developmental Psychology, 34(4), 471-488. doi: 10.1111/bjdp.12144

Sette, S., Baumgartner, E., \& Schneider, B. H. (2014). Shyness, child-teacher relationships, and socio-emotional adjustment in a sample of Italian preschool-aged children. Infant and Child Development, 23(3), 323-332. doi:10.1002/icd.1859

Shields, A. M., \& Cicchetti, D. (1997). Emotion regulation among school-age children: The development and validation of a new criterion Q-sort scale. Developmental Psychology, 33, 906-916. doi:10.1037/0012-1649.33.6.906.

Shipman, K. L., Schneider, R., Fitzgerald, M. M., Sims, C., Swisher, L., \& Edwards, A. (2007). Maternal emotion socialization in maltreating and non-maltreating families: Implications for children's emotion regulation. Social Development, 16(2), 268-285. doi:

10.1111/j.1467-9507.2007.00384.x 
Shortt, J. W., Stoolmiller, M., Smith-Shine, J. N., Eddy, J. M., \& Sheeber, L. (2010). Maternal emotion coaching, adolescent anger regulation, and siblings' externalizing symptoms. Journal of Child Psychology and Psychiatry, 51, 799-808.

Silk, J. S., Shaw, D. S., Skuban, E. M., Oland, A. A., \& Kovacs, M. (2006). Emotion regulation strategies in offspring of childhood-onset depressed mothers. Journal of Child Psychology and Psychiatry, 47(1), 69-78. doi:10.1111/j.1469-7610.2005.01440.x

Smith, P. K. (1978). A longitudinal study of social participation in preschool children: Solitary and parallel play reexamined. Developmental Psychology, 14(5), 517-523.

Song, J., Colasante, T., \& Malti, T. (2017). Helping yourself helps others: Linking children's emotion regulation to prosocial behavior through sympathy and trust. Emotion. Advance online publication. doi: 10.1037/emo0000332

Spinrad, T. L., Eisenberg, N., Cumberland, A., Fabes, R. A., Valiente, C., Shepard, S. A., ... \& Guthrie, I. K. (2006). Relation of emotion-related regulation to children's social competence: A longitudinal study. Emotion, 6(3), 498-519. doi:10.1037/15283542.6.3.498

Spinrad, T. L., Eisenberg, N., Harris, E., Hanish, L., Fabes, R. A., Kupanoff, K., ... \& Holmes, J. (2004). The relation of children's everyday nonsocial peer play behavior to their emotionality, regulation, and social functioning. Developmental Psychology, 40(1), 6780. doi:10.1037/0012-1649.40.1.67

Stewart, S. L., \& Rubin, K. H. (1995). The social problem-solving skills of anxious-withdrawn children. Development and Psychopathology, 7(2), 323-336. 
Suveg, C., Kendall, P. C., Comer, J. S., \& Robin, J. (2006). Emotion-focused cognitive behavioral therapy for anxious youth: A multiple-baseline evaluation. Journal of Contemporary Psychotherapy, 36,77-85. doi:10.1007/s10879-006-9010-4

Suveg, C., \& Zeman, J. (2004). Emotion regulation in children with anxiety disorders. Journal of Clinical Child and Adolescent Psychology, 33(4), 750-759. doi:10.1207/s15374424jccp3304_10 ·

Theall-Honey, L. A., \& Schmidt, L. A. (2006). Do temperamentally shy children process emotion differently than nonshy children? Behavioral, psychophysiological, and gender differences in reticent preschoolers. Developmental Psychobiology, 48(3), 187-196.

Thomas, A., \& Chess, S. (1977). Temperament and Development. New York: Brunner/Mazel. Thompson, R. A. (2011). Emotion and emotion regulation: Two sides of the developing coin. Emotion Review, 3(1), 53-61. doi: 10.1177/1754073910380969

Thompson, R. A., \& Goodman, M. (2009). Development of emotion regulation: More than meets the eye. In A. M. Kring \& D. M. Sloan (Eds.), Emotion Regulation and Psychopathology, (pp. 38-58). New York, NY: Guilford.

Walker, O. L., Henderson, H. A., Degnan, K. A., Penela, E. C., \& Fox, N. A. (2014). Associations between behavioral inhibition and children's social problem-solving behavior during social exclusion. Social Development, 23(3), 487-501. doi: $10.1111 /$ sode. 12053

Waters, S. F., \& Thompson, R. A. (2014). Children's perceptions of the effectiveness of strategies for regulating anger and sadness. International Journal of Behavioral Development, 38(2), 174-181. 
Williams, S. R., \& Woodruff-Borden, J. (2015). Parent emotion socialization practices and child self-regulation as predictors of child anxiety: The mediating role of cardiac variability. Child Psychiatry and Human Development, 46, 512-522. doi: 10.1007/s10578-014-04920

Wilson, K. R., Havighurst, S. S., \& Harley, A. E. (2012). Tuning in to kids: An effectiveness trial of a parenting program targeting emotion socialization of preschoolers. Journal of Family Psychology, 26(1), 56-65. doi: 10.1037/a0026480

Wu, Q., Feng, X., Hooper, E., \& Ku, S. (2017). Maternal emotion socialization, depressive symptoms and child emotion regulation: Child emotionality as a moderator. Infant and Child Development, 26(1), 1-22. doi:10.1002/icd.1979

Yang, L., Zou, X., \& Bergen, D. (1995). The development of social and cognitive complexity in preschoolers' play: A cross-cultural comparison. Acta Psychologica Sinica, 27(1), 84-90.

Zeman, J., Shipman, K., \& Suveg, C. (2002). Anger and sadness regulation: Predictions to internalizing and externalizing symptoms in children. Journal of Clinical Child \& Adolescent Psychology, 31(3), 393-398. doi :10.1207/S15374424JCCP3103_11

Zimmermann, P., Maier, M. A., Winter, M., \& Grossman, K. E. (2001). Attachment and adolescents' emotion regulation during a joint problem-solving task with a friend. International Journal of Behavioral Development, 25(4), 331-343. doi:

$10.1080 / 01650250143000157$ 


\section{Appendix A \\ Emotion Regulation Skills Questionnaire \\ (Mirabile, 2014)}

Listed below are a number of statements which parents, caregivers, and teachers use to describe how children respond to different feelings and situations. Please read each statement and respond as honestly as you can. There are no right or wrong answers. Circle the number to show how often your child uses each strategy.
Never
Rarely
1
Sometimes
2
Often
3
Almost Always
4

Think about when your child gets ANGRY (for example, when s/he wants something but can't have it, when s/he has to wait for something s/he wants), and please rate how often your child does the following behaviors when s/he gets ANGRY. 1. S/he calms him/herself by talking through the problem (e.g., "I'm a big boy;" "I just have to wait
a little longer").
012234
2. S/he tries to get the object s/he can't have. $\quad$\begin{tabular}{llll}
0 & 1234 \\
\hline
\end{tabular}
3. S/he asks questions about the forbidden object or why s/he cannot have it (e.g., "When do I get $\quad \begin{array}{lllll}0 & 1 & 2 & 3\end{array}$ my present?", "When can I have the candy?", "Why can't I have the cookie?")
4. S/he watches or stares at the forbidden object (e.g., a candy or toy). $\quad 012234$

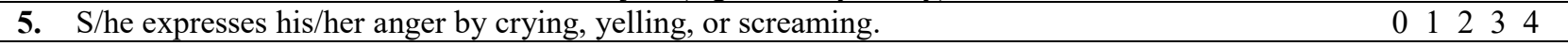
6. S/he shows his/her anger by banging, kicking, throwing things, or hitting things or people. $\quad \begin{array}{rllll}0 & 1234\end{array}$

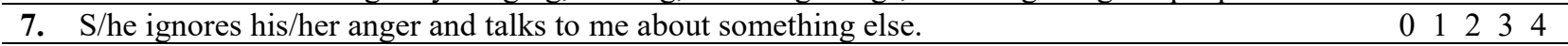
8. S/he ignores whatever is making him/her angry and finds a toy to play with, sings, dances, runs $\begin{array}{lllll}0 & 1234\end{array}$ around, or finds something else to do.
9. S/he comforts him/herself by thumb sucking, playing with his/her hair, looking at or playing with $\quad \begin{array}{llllll}0 & 1 & 2 & 4\end{array}$ parts of his/her body or clothes (e.g., fingers, buttons, zippers), or uses a teddy or blanket.
10. S/he comes to me for comfort (e.g., reaches up to me, asks me for a hug, climbs into my lap, $\quad \begin{array}{lllll}0 & 1234\end{array}$ wants to be held).
11. S/he asks me for help in fixing the problem (e.g., getting another child to share).
12. S/he asks, threatens, or does run away from what is making him/her angry, leaves the room, or looks away from it.
\begin{tabular}{lllll}
0 & 1 & 2 & 3 & 4 \\
\hline
\end{tabular}

$\begin{array}{lllllllll}0 & 1 & 2 & 3 & 4\end{array}$
13. $\mathrm{S} /$ he tries to hold his/her anger inside and/or does not want to show how $\mathrm{s} / \mathrm{he}$ feels.
012234

Think about when your child gets AFRAID or SCARED (for example, when s/he is watching a scary movie, meets an unfamiliar person or animal) and please rate how often your child does the following behaviors when s/he gets AFRAID or SCARED.

14. S/he calms him/herself by talking through the problem (e.g., "I'm a big boy;" "This is just $\quad \begin{array}{llll}0 & 1234\end{array}$ pretend").
15. $\mathrm{S} /$ he tries to face the situation and deal with it.
012234
16. S/he asks questions about the event or object (e.g., "Will it hurt me?" or "Is this pretend or make- $\begin{array}{llllllllll}0 & 1 & 2 & 4\end{array}$ believe?" or "It's just TV/a movie, right?")
\begin{tabular}{llllll}
\hline 17. S/he watches or stares at what makes him/her afraid. & 0 & 12 & 3 & 4 \\
\hline 18. S/he shows his/her fear by crying, yelling, or screaming. & 0 & 1 & 2 & 3 & 4 \\
\hline 19. S/he shows his/her fear by banging, kicking, throwing things, or hitting things or people. & 0 & 1 & 2 & 3 & 4 \\
\hline 20. S/he ignores whatever makes him/her afraid and talks to me about something else. & 0 & 1 & 2 & 3 & 4 \\
\hline 21. S/he ignores whatever makes him/her afraid and finds a toy to play with, sings, dances, & 0 & 1 & 2 & 3 & 4
\end{tabular} runs around, or finds something else to do.

22. S/he comforts him/herself by thumb sucking, playing with his/her hair, looking at or playing with $\quad \begin{array}{lllll}0 & 1 & 2 & 3 & 4\end{array}$ parts of his/her body or clothes (e.g., fingers, buttons, zippers), or uses a teddy or blanket.

23. S/he comes to me for comfort (e.g., reaches up to me, asks me for a hug, climbs into my lap, $\quad \begin{array}{lllll}0 & 1234\end{array}$ wants to be held). 
24. S/he asks me for help in fixing the problem (e.g., asking to turn off a scary movie, put away a scary toy, leave a scary place).

25. S/he asks, threatens, or does run away from what makes him/her afraid, leaves the room, or looks $\quad \begin{array}{llllll}0 & 1 & 2 & 3 & 4\end{array}$ away from it.

26. S/he tries to hold his/her fear inside and/or does not want to show how s/he feels.

012234

\section{SUBSCALES}

Adaptive Strategies

Self-directed Speech/Symbolic Self-Soothing (SD). These items reflect the degree to which a child responds to intense emotion by talking to him/herself.

Scoring: Mean of: 1, 14

Constructive/Instrumental Coping (IC). These items reflect the degree to which a child responds to intense emotion by attempting to address/change/fix the emotion elicitor.

Scoring: Mean of: 2,15

Information Gathering (IG). These items reflect the degree to which a child responds to intense emotion by gathering information/asking questions about the emotion elicitor.

Scoring: Mean of: 3, 16

Self Comforting/Soothing (SC). These items reflect the degree to which a child responds to intense emotion by engaging in self-comforting/stimulatory behaviors.

Scoring: Mean of: 9, 22

Comfort Seeking (CS). These items reflect the degree to which a child responds to intense emotion by soliciting the comforting/soothing of a caregiver.

Scoring: Mean of: 10, 23

Support Seeking (SS). These items reflect the degree to which a child responds to intense emotion by soliciting the help/assistance of a caregiver.

Scoring: Mean of: 11, 24

Verbal/Other-oriented Distraction (VD). These items reflect the degree to which a child responds to intense emotion by talking to a caregiver about an unrelated topic.

Scoring: Mean of: 7, 20

Self/Object Oriented Distraction (OD). These items reflect the degree to which a child responds to intense emotion by engaging in an alternate activity unrelated to the stressor.

Scoring: Mean of: 8,21

Maladaptive Strategies

Focus on Distressing Object/Situation (OF). These items reflect the degree to which a child responds to intense emotion by only focusing their attention on the emotion elicitor.

Scoring: Mean of: 4, 17

Venting (VN). These items reflect the degree to which a child responds to intense emotion by expressing that emotion verbally or physically.

Scoring: Mean of: 5,18

Aggression (AG). These items reflect the degree to which a child responds to intense emotion by physically attacking the stressor or an(other) object or individual.

Scoring: Mean of: 6, 19 
Avoidance (AV). These items reflect the degree to which a child responds to intense emotion by attempting to or actually removing themselves from the situation or removing the stressor from their attention.

Scoring: Mean of: 12, 25

Suppression (SU). These items reflect the degree to which a child responds to intense emotion by attempting to minimize their external display of the emotion.

Scoring: Mean of: 13, 26, 


\section{Appendix B}

\section{Tell uS AbOUT Your ChILd}

Please answer the items on this page about the behavior of your child by circling one of the numbers following each item. We know that no item will apply to the child in every situation, but try to consider his/her usual or general behavior. Please answer all questions - there are no right or wrong answers.

How much is your child like that?

1. My child often seems content to play alone.

$\begin{array}{llll}\text { Not at All } & \leftarrow \rightarrow & \text { A Lot } \\ 1 & 2 & 3 & 4\end{array}$

2. My child seems to want to play with other children, but is sometimes nervous to.

3. My child is just as happy to play quietly by his/herself than to play with a group of children.

4. My child actively avoids playing with other children.

5. My child is happiest when playing with other children.

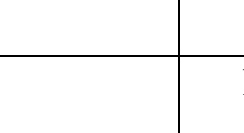

$\begin{array}{lllll}1 & 2 & 3 & 4 & 5\end{array}$

6. My child will turn down social initiations from other children because he/she is 'shy'.

7. My child does not want to play with other children.

\begin{tabular}{l|lllll} 
& 1 & 2 & 3 & 4 & 5 \\
\hline
\end{tabular}

8. My child often approaches other children to initiate play.

1

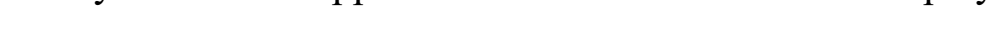

9. My child often goes out of his/her way not to play with other children.

10. My child 'hovers' near where other children are playing, without joining in.

11. My child rarely initiates play activities with other children.

12. If given the choice, my child prefers to play with other children rather than alone.

13. My child will often turn down social invitations from other children because he/she wants to be alone.

\begin{tabular}{|c|c|c|c|c|c|}
\hline $\begin{array}{l}\text { 14. My child often watches other children play without approaching } \\
\text { them. }\end{array}$ & 1 & 2 & 3 & 4 & 5 \\
\hline $\begin{array}{l}\text { 15. Although he/she appears to desire to play with others, my child is } \\
\text { sometimes anxious about interacting with other children }\end{array}$ & 1 & 2 & 3 & 4 & 5 \\
\hline
\end{tabular}




\section{Appendix C}

TELL US AbOut YourselF

On this page you will see statements that describe feelings in yourself and your child. We would like to know your opinions about each of these statements. For each statement please decide to what extent you agree or disagree and circle your choice. Please remember that there are no right or wrong answers. And please use the following scale to indicate the extent to which you agree with the statements:

$$
1 \text { strongly disagree } \quad 2=\text { disagree } 3=\text { neutral } \quad 4=\text { agree } \quad 5=\text { strongly agree }
$$

1. When my child is sad, it's time to problem solve.

$\begin{array}{lllll}1 & 2 & 3 & 4 & 5\end{array}$

2. Anger is an emotion worth exploring.

$\begin{array}{lllll}1 & 2 & 3 & 4 & 5\end{array}$

3. When my child is sad I am expected to fix the world and make it

$\begin{array}{lllll}1 & 2 & 3 & 4 & 5\end{array}$
perfect.

4. When my child gets sad, it's a time to get close.

$\begin{array}{lllll}1 & 2 & 3 & 4 & 5\end{array}$

5. Sadness is something that one has to get over, to ride out, not to dwell on.

6. I prefer my child to be happy rather than overly emotional.

$\begin{array}{lllll}1 & 2 & 3 & 4 & 5\end{array}$
7. I help my child get over sadness quickly so he/she can move onto other things.

\begin{tabular}{|c|c|c|c|c|c|}
\hline 8. When my child is angry, it's an opportunity for getting close. & 1 & 2 & 3 & 4 & 5 \\
\hline $\begin{array}{l}\text { 9. When my child is angry, I take some time to try to experience this } \\
\text { feeling with him/her. }\end{array}$ & 1 & 2 & 3 & 4 & 5 \\
\hline 10. I try to change my child's angry moods into cheerful ones. & 1 & 2 & 3 & 4 & 5 \\
\hline $\begin{array}{l}\text { 11. Childhood is a happy-go-lucky time, not a time for feeling sad or } \\
\text { angry. }\end{array}$ & 1 & 2 & 3 & 4 & 5 \\
\hline 12. When my child gets angry my goal is to get him/her to stop. & 1 & 2 & 3 & 4 & 5 \\
\hline 13. When my child is angry I want to know what he/she is thinking. & 1 & 2 & 3 & 4 & 5 \\
\hline 14. When my child is angry, it's time to solve a problem. & 1 & 2 & 3 & 4 & 5 \\
\hline
\end{tabular}


Child's name

Rated by (teacher)

\section{Appendix D}

Date School

\section{Child Behavior Scale}

Please consider the descriptions contained in each of the following items below and rate the extent to which each of these descriptions applies to this child, particularly in the context of his/her behavior with peers. For example, circle 3-"Certainly applies" if the child often displays the behavior described in the statement, circle 2-"Applies sometimes" if the child occasionally displays the behavior, and circle 1-"Doesn't apply" if the child seldom displays the behavior. Please circle only one response per item.

$\underline{1=\text { Doesn't apply } \quad 2=\text { Applies sometimes } \quad 3=\text { Certainly applies }}$

123 1. Restless. Runs about or jumps up and down. Doesn't keep still

$\begin{array}{llll}2 & 2 & 2 & 2\end{array}$. Squirmy, fidgety child

123 3. Fights with other children

1234 . Not much liked by children

1235 . Is worried. Worries about many things

1236 . Appears miserable, unhappy, tearful, or distressed

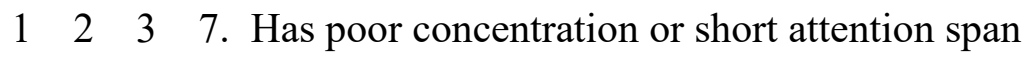

1238 . Tends to be fearful or afraid of new things or new situations

$\begin{array}{llll}1 & 2 & 3 & 9\end{array}$. Bullies other children

12310 . Inattentive

123 11. Cries easily

123 12. Kicks, bites or hits other children

123 13. Prefers to play alone

123 14. Helps other children

12315 . Peers refuse to let this child play with them 
123 16. Shows a recognition of the feelings of others; is empathetic

$\underline{1=\text { Doesn't apply } \quad 2=A p p l i e s ~ s o m e t i m e s ~} \quad 3=$ Certainly applies

123 17. Not chosen as playmate by peers

123 18. Likes to be alone

123 19. Keeps peers at a distance

1232 20. Peers avoid this child

1232 21. Seems concerned when other children are distressed

12322 . Aggressive child

1232 23. Taunts and teases other children

$\begin{array}{llll}1 & 2 & 3 & 24 .\end{array}$ Threatens other children

12325 . Kind toward peers

1232 . Excluded from peers' activities

$\begin{array}{llll}1 & 2 & 3 & 27 .\end{array}$. Is ignored by peers

12328 . Cooperative with peers

12329 . Argues with peers

12330 . Solitary child

123 31. Shows concern for moral issues (e.g., fairness, welfare or others)

123 32. Ridiculed by peers

123 33. Avoids peers

12334 . Offers help or comfort when other children are upset

12335 . Withdraws from peer activities 
Hello

\section{Appendix E}

We are researchers from Carleton University, writing to invite the name of childcare centre to participate in the "Children's Feelings Study", a new project that we undertaking in local preschools and childcare centres. In this study, we are trying to learn more about how young children learn to control their emotions, and how the expression of emotions such as fear and anger can impact upon children's early social experiences with peers.

This research is under the supervision of Dr. Robert Coplan, a Professor in the Department of Psychology at Carleton University. This study has also been approved by the Carleton University Research Ethics Board-B (\#104810, August 2016).

If your childcare centre agrees to participate - here is what would be involved. First, we would send home an information letter, consent form, and questionnaire packet to parents of children aged 3-5 years at your centre. We would ask parents to return these forms to the centre in a sealed envelope (where we would collect them). Children who receive parental consent will be invited to participate in a short (5-minute) one-on-one interview with a trained researcher (scheduled at your convenience). Our timetable is quite flexible and we would be happy to accommodate any request in terms of when we could start. Early childhood educators would also be invited to complete a short questionnaire for only this subset of children (i.e., those whose parents give consent). These questionnaires would take less than 5 minutes to complete for each child. As a small token on our appreciation, we will donate a children's book to the centre's library.

We know you are busy! Your help with this research would be greatly appreciated. If you think you might be interested in participating, please see the attached information letter for parents for more details about the study. I would also be more than happy to set up a meeting (in person or by phone) to further discuss the study. You can contact me directly via email at: william.hipson@carleton.ca, and you can reach Dr. Coplan at: robert.coplan@carleton.ca For more information about the research we do - please see: www.carleton.ca/ rcoplan/ Thank you and we look forward to hearing from you!

Will Hipson, MA student

Department of Psychology

Carleton University

1125 Colonel By Drive, Ottawa, ON, Canada, K1S 5B6

william.hipson@carleton.ca

tel:

Robert J. Coplan, PhD

Director, Pickering Centre for Research in Human Development

Professor, Department of Psychology

Carleton University

robert.coplan@carleton.ca

tel: 613-520-2600 ext. 8691 


\section{Appendix F}

Dear Parent,

I am writing to ask your permission for your child to participate in the Children's Feelings Study, a new research project that is being conducted at your child's preschool/childcare centre. We are trying to learn more about how emotions develop, and in particular, how children learn to cope with their feelings. Children experience many emotions throughout the day - some are more positive (like happiness) and others can be viewed more negatively (like fear or anger). For young children, an important part of navigating their social worlds is learning when and how to control emotions - particularly when their feelings get too "big"! How children express and deal with emotions can have an important influence on their day to day social interactions with peers.

This type of research is important because it will help us better understand how children's emotions relate to their social experiences - which in turn can lead to improvements in how to best assist children who may sometimes struggle to engage with peers. Here is a more detailed description of what this project will involve (if you choose to participate):

Parents: Parents are being asked to complete some short questionnaires. The first concerns background information that will be used only to characterize this sample. Other questionnaires ask parents to describe themselves or their children. These questionnaires are attached for your inspection. If you agree to participate in this study - please complete the attached questionnaires and return them to your child's childcare/preschool sealed in the envelope provided. You are free to not answer any questions that you choose to omit. The total time estimated to complete all portions of this study is 20 minutes.

Teachers: Your child's teacher will be asked some questions about how your child gets along with other children at preschool/childcare.

Children: Children ages 3-5 attending the childcare centre will be invited to participate in a short ( 5 minutes) interview with a trained research assistant. Interviews will be conducted in a location chosen by your child's childcare (e.g., if possible, in a quiet corner of the classroom/play area), during a time period selected to minimize the disruption of your child's normal daily routine. Your child will be asked a few questions about what kinds of activities they prefer to do alone or with friends. Although there are no explicit risks to this study, your child may become bored or restless during the interview. Your child will be reminded that they do not have to answer any questions they don't want to, and of course, they are free to end the interview at any time.

All researchers associated with this project have had police record checks and will have their police record check present at the time of the interview. The information collected in this study is strictly confidential and will be made available only to researchers associated with this project, unless it suggests that a child is experiencing physical and/or psychological harm, or it is foreseeable that this harm may occur in the future. Your child's name will be changed to a numerical code on all corresponding forms in order to maintain confidentiality. All questionnaires will be used only to gather information for data analysis, and individual questionnaire feedback will not be made available. All data will be stored in a secure location (locked office designated for all data), and all personal information will be destroyed 5 years after the completion of the study. 
You and your child have the right to withdraw participation or data at any time without any penalty or questions. In such an event, any and all information collected on your child to that point will be destroyed. This research is funded by the Social Sciences and Humanities Research Council and an Ontario Graduate Scholarship. This study has been approved by the Carleton University Research Ethics Board-B (\#104810, August 2016).

If you have any questions related to this study and/or concerns about your child as a result of participation in this study, please feel free to contact me directly at 902-233-0822 (or via e-mail at: william.hipson@carleton.ca) or my faculty advisor, Dr. Robert Coplan (robert.coplan@,carleton.ca, 613-520-2600 ext. 8691). Should you have any ethical concerns about this study, please contact Dr. S. Brown (Chair, Carleton University Research Ethics Board - B, 520-2600, ext. 1505) or the Carleton University Research Office (ethics@,carleton.ca). If you would like to learn more about young children's development, an excellent resource is the Encyclopedia of Early Childhood Development (http://www.child-encyclopedia.com/enca/home.html).

Sincerely,

Will Hipson, MA student

Department of Psychology

Carleton University

phone:

e-mail: william.hipson@,carleton.ca 


\section{Appendix G}

\section{Parent Consent Form}

The information collected for this project is confidential and protected under the Municipal Freedom of Information and Privacy Act, 1989.

It is necessary to obtain informed consent from you. This means you are willing to participate and are aware of the procedures and purpose of this study.

This study has received clearance by the Carleton University Research Ethics Board-B (\#104810, August 2016)

Date:

(Name of child - please print)

(Name of parent or guardian - please print)

Child's age

Child's gender

Name of child's preschool/childcare centre

Please check one:

I give my permission for my child and me to participate in the Children's Feelings Study

$\frac{}{\text { Study }}$ I do not give my permission for my child and me to participate the Children's Feelings

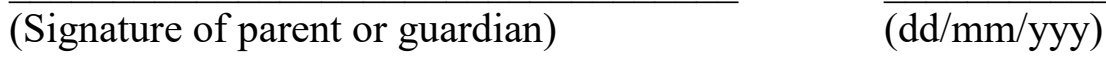

Please include your e-mail address:

Please include your telephone number:

Please return the signed consent form and questionnaires to your child's educator (sealed in the enclosed envelope) as soon as possible even if you are not going to be participating in the study. 


\section{Appendix H}

\section{Background Information - PARENTS}

The following information is gathered in order to get a better overall understanding of the participants involved. All information is confidential. No personal information will be released.

Child's Name:

Child's age:

Boy: _ Girl:

Child's daycare

Mother's highest level of formal education completed (please check one):

Elementary school

High school diploma or equivalent

Community college or equivalent

University degree

Graduate school degree

Father's highest level of formal education completed (please check one):

Elementary school

High school diploma or equivalent

Community college or equivalent

University degree

Graduate school degree

Parents' Marital status (please check one):

Married/Common Law

Single

Divorced/Separated

Other

Mother's ethnic group (optional):

Caucasian

Asian

Hispanic

Aboriginal

Black

Other 


\section{Appendix I}

Dear Parent,

We are so grateful for you and your child's participation in the Children's Feelings Study!

We are trying to learn more about how emotions develop, and in particular, how children learn to cope with their feelings. For example, we have been exploring how children's expression of emotions can influence their day to day social interactions with peers. We will e-mail you with a summary of our findings when they become available.

If you have any questions related to this study and/or concerns about your child as a result of participation in this study, please feel free to contact me directly at 902-233-0822 (or via e-mail at: william.hipson@carleton.ca) or my faculty advisor, Dr. Robert Coplan

(robert.coplan@carleton.ca, 613-520-2600 ext. 8691). Should you have any ethical concerns about this study, please contact Dr. S. Brown (Chair, Carleton University Research Ethics Board-B, 5202600, ext. 1505) or the Carleton University Research Office (ethics@carleton.ca).

If you would like to learn more about young children's development, an excellent resource is the Encyclopedia of Early Childhood Development (http://www.child-encyclopedia.com/enca/home.html). If you have any concerns about your child's socio-emotional well-being, additional information, resources, and support can be found via the Parent Resource Centre (613565-2467, http://www.parentresource.ca/en/ottawaprc/index.php).

Thank you again for your participation - we could not do this without you!!

Sincerely,

Will Hipson, MA student

Department of Psychology

Carleton University

phone:

e-mail:william.hipson@carleton.ca 


\section{Appendix J}

\section{Dear Educator,}

I am writing to ask your permission to participate in Children's Feelings Study, a new research project that is being conducted at your preschool/childcare centre. We are trying to learn more about how emotions develop, and in particular, how children learn to cope with their feelings. Children experience many emotions throughout the day - some are more positive (like happiness) and others can be viewed more negatively (like fear or anger). For young children, an important part of navigating their social worlds is learning when and how to control emotions particularly when their feelings get too "big"! How children express and deal with emotions can have an important influence on their day to day social interactions with peers. This type of research is important because it will help us better understand how children's emotions relate to their social experiences - which in turn can lead to improvements in how to best assist children who may sometimes struggle to engage with peers. Here is a more detailed description of what this project will involve (if you choose to participate):

Your participation would involve completing a short questionnaire concerning children's social behaviors at school for a small subset of children in your class who have received parental consent to participate. The questionnaire should take less than 5 minutes to complete per child. You are free to not answer any questions that you choose to omit. If you agree to participate in this study - please complete the attached questionnaires and place them sealed in the envelope to be later picked up by a member of the research team. The information you provide will remain confidential, unless it suggests that a child is experiencing physical and/or psychological harm, or it is foreseeable that this harm may occur in the future. There are no anticipated risks in your participation in this study. Only the researchers associated with this project have access to the data. Your signed consent form will be kept in a secure environment (a data room that is locked and will only be accessed by the faculty researcher and study co-ordinator) and will be destroyed after 5 years. Your participation is strictly voluntary and you have the right to withdraw participation or data at any time without any penalty or questions. This research is funded by the Social Sciences and Humanities Research Council and an Ontario Graduate Scholarship. This study has been approved by the Carleton University Research Ethics Board-B (\#104810, August 2016).

If you have any questions related to this study and/or concerns about your child as a result of participation in this study, please feel free to contact me directly at 902-233-0822 (or via e-mail at: william.hipson@carleton.ca) or my faculty advisor, Dr. Robert Coplan (robert.coplan@carleton.ca, 613-520-2600 ext. 8691). Should you have any ethical concerns about this study, please contact Dr. S. Brown (Chair, Carleton University Research Ethics BoardB, 520-2600, ext. 1505) or the Carleton University Research Office (ethics@carleton.ca).

Will Hipson, MA student

Department of Psychology

Carleton University

phone:

e-mail: william.hipson@carleton.ca 


\section{Appendix K}

\section{Educator Consent Form}

The information collected for this project is confidential and protected under the Municipal Freedom of Information and Privacy Act, 1989.

It is necessary to obtain informed consent from you. This means you are willing to participate and are aware of the procedures and purpose of this study.

This study has received clearance by the Carleton University Research Ethics Board-B (\#104810, August 2016)

Date:

(Name - please print)

(Name of preschool/childcare centre - please print)

Please check one:

I agree to participate in the Children's Feelings Study

I do not agree to participate the Children's Feelings Study

(Signature)

$(\mathrm{dd} / \mathrm{mm} / \mathrm{yyy})$

If you would like to receive a summary of the findings from this study please indicate an e-mail address to which we can send the results. Please note that only group results will be provided, and not individual feedback about particular children. 


\section{Appendix L}

\section{Dear Educator,}

We are so grateful for your participation in the Children's Feeling Study!

We are trying to learn more about how emotions develop, and in particular, how children learn to cope with their feelings. For example, we have been exploring how children's expression of emotions can influence their day to day social interactions with peers. We will email you with a summary of our findings when they become available.

If you have any questions related to this study and/or concerns about your child as a result of participation in this study, please feel free to contact me directly at 902-233-0822 (or via e-mail at: william.hipson@carleton.ca) or my faculty advisor, Dr. Robert Coplan (robert.coplan@carleton.ca, 613-520-2600 ext. 8691). Should you have any ethical concerns about this study, please contact Dr. S. Brown (Chair, Carleton University Research Ethics Board-B, 5202600, ext. 1505) or the Carleton University Research Office (ethics@carleton.ca).

If you would like to learn more about young children's development, an excellent resource is the Encyclopedia of Early Childhood Development (http://www.child-encyclopedia.com/enca/home.html).

Thank you again for your participation - we could not do this without you!!

Sincerely,

Will Hipson, MA student

Department of Psychology

Carleton University

phone:

e-mail: william.hipson@carleton.ca 